\title{
Fännikultuuri loomine koroonakriisis Eesti ja Valgevene jalgpallijuhtumite näitel
}

\author{
Anastasiya Fiadotava \\ Eesti Kirjandusmuuseumi folkloristika osakonna nooremteadur \\ anastasiya.fiadotava@folklore.ee \\ Piret Voolaid \\ Eesti Kirjandusmuuseumi folkloristika osakonna vanemteadur \\ Eesti-uuringute Tippkeskuse tegevjuhi ülesannetes \\ piret.voolaid@folklore.ee
}

Teesid: Võrdlev uurimus analüüsib spordikultuuri ja koroonakriisi vahekordi kahe teineteisest füüsiliselt sadade kilomeetrite kaugusel asuva riigi - Eesti ja Valgevene - fännirühmituste näitel. Sport ja koroonapandeemia on väga tihedasti seotud. Eesti koroonajuhtumi kohta lubavad ametlikud analüüsitulemused väita, et esimese laine ajal koroonaviirusest kõige rohkem räsitud maakonnas Saaremaal sõna otseses mõttes puhuti viirus laiali 4. ja 5. märtsil 2020 toimunud rahvusvahelisel võrkpallivõistlusel fännipasunatest. Valgevene spordiüritustel polnud nii dramaatilised järelmõjud, aga mõnedes populaarsetes spordiklubides olid koroonaviiruse kolded. Riigid suhtusid spordiüritustesse erinevalt. Eestis, nagu enamikus Euroopa riikides, olid kõik spordivõistlused ja platsimängud 12. märtsist 17. maini 2020 kehtinud eriolukorra ajal keelatud, Valgevenes jätkus aga tavapärane spordielu (välja arvatud juhtumid, kui spordiklubis oli viiruskolle). Samal ajal kui Eesti jalgpallifännid olid sunnitud kodus püsima ja mängude jätkumist ootama, nautisid Valgevene vutisõbrad erinevalt muust maailmast meistriliiga mänge ja staadionimelu. Valgevene ainulaadne olukord suunas maailma jalgpallifännide tähelepanu Valgevene jalgpallile. Pandeemia ajal toimus enamik fännide tegevusi veebikeskkonnas (online), mistõttu sai sotsiaalmeedia käesoleva ühisuurimuse sobivaimaks keskkonnaks.

Artiklis võrdleme Eesti ja Valgevene jalgpalliklubide tegevust COVID-19 viiruse leviku n-ö esimese laine ajal ja analüüsime, milliste mehhanismidega jätkus fännitegevus Facebookis. Ühtlasi kirjeldame laiemalt spordi olukorda pandeemia ajal.

Märksõnad: COVID-19 pandeemia, eesti ja valgevene folkloor, fännikultuur, huumor, internetimeemid, jalgpall, koroonapärimus, spordifolkloor, sotsiaalmeedia 


\section{Sissejuhatus}

Nii nagu paljud teised kultuurivaldkonnad, sattus sport 2020. aasta koroonapandeemia ajal eri riikides keerulisse olukorda. Enamikus Euroopa riikides ja maailmas laiemalt olid spordivõistlused esimesed ohvrid - need keelati ära, et kaitsta nii sportlasi kui ka pealtvaatajaid-fänne. Tuleb aga tähele panna, et kehtima hakanud eriolukord katkestas küll võistlused, kuid sportlaste ja fännide tegevus jätkus teistes kanalites.

Riigid, sh käesolevas artiklis analüüsitavad Eesti ja Valgevene suhtusid viiruse tõkestamisega seotud piirangutesse ja spordiüritustesse erinevalt. Eestis, nagu enamikus Euroopa riikides, olid kõik spordivõistlused 12. märtsist 17. maini kehtinud eriolukorra ajal keelatud. Valgevenes aga koroonaviiruse leviku tõttu eriolukorda ei kehtestatud ja spordielu jätkus tavalisel moel.

Käesoleva ühisuurimuse huviorbiidis on jalgpall kui üks laialdasema publikuhuviga spordiala maailmas. ${ }^{1}$ Jalgpalli olukord COVID-19 pandeemia ajal on pälvinud juba eri valdkonna tähelepanu. Näiteks ajakirja Soccer \& Society 2021. aasta avanumber on täienisti pühendatud jalgpallimaailmale koroonaajal, selles on vaatluse all nt pandeemia mõju jalgpallikohtunike tegevusele (Webb 2021; Boschilia \& Moraes \& Marchi Junior 2021), ajakirjanike-jalgpallikommentaatorite elule (Woodward 2021; Horky 2021), äritegevusele (Parnell \& Bond \& Widdop \& Cockayne 2021), Inglise kõrgliiga jalgpalliklubidele (Kennedy \& Kennedy 2020), jalgpallurite füüsilisele jõudlusele ja vigastuste esinemissagedusele (Guerrero-Calderon 2021). Esineb võrdlevaid käsitlusi ka mängupausi kohta Teise maailmasõja ja koroonapandeemia ajal (Tovar 2021).

Meie ühisartikkel pakub veel ühe originaalse vaatenurga koroonaaja jalgpallile. Folkloristliku uurimuse eesmärk on võrrelda Eesti ja Valgevene jalgpalliklubide tegevust koroonapandeemia esimese laine ajal märtsist maini 2020 ja selgitada välja toimetulekustrateegiad. Vastame uurimisküsimusele, kuidas jätkus klubide suhtlemine fännidega ja fännitegevus sotsiaalmeedias, täpsemalt portaalis Facebook. Hoolimata Eesti ja Valgevene jalgpalli erinevast olukorrast koroonakriisis oli veebikeskkond mõlemal juhul vutisõprade põhiline suhtluspaik, mistõttu kujunes sotsiaalmeediast käesoleva ühisuurimuse sobivaim keskkond.

Fännikultuuri konstrueerimist koroonakriisi ajal analüüsime kolmest üksteisega põimuvast aspektist. Esiteks käsitleme jalgpallifänne kui subkultuuri sotsiaalmeedias, tuues välja ametliku klubitegevuse ja rohujuuretasandi vastasmõju. Kui rahvusvahelised tippklubid tunnetavad oma globaalset tähendust ja suunavad oma sõnumid sotsiaalmeedias fännidele kogu maailmas, siis väiksemate ja vähem tuntud klubide toetus on väga lokaalne. Kohalike klubide toetajad suhtlevad peamiselt staadionitel ja pubides (ning põlgavad 
sageli fänne, kes eelistavad liigamänge telerist vaadata, vt Richardson \& Turley 2006), samuti ei mängi nende sotsiaalmeedia rühmad fännikogukondades nii otsustavat rolli.

Teiseks mõtestame jalgpallurite ja fännide omavahelist suhtlust sotsioloogiast ja psühhiaatriast pärit parasotsiaalse suhtluse mõiste ja sellega kaasneva imaginaarse tagasiside abil (Horton \& Wohl 1956). Tuginedes David Gilesi (nt 2002; 2010: 451) ideele, et parasotsiaalne suhtlus on üksikisikute võimalike kohtumiste spektri ühes otsas, väidame, et jalgpallurite ja nende veebifännide vahelised suhted töötavad sotsiaalse ja parasotsiaalse suhtluse koostoimel.

Kolmandaks uurime, millised naljad ja milliste huumoritehniliste mehhanismidega olid koroonaajal jalgpalliklubide sotsiaalmeediategevuse kaudu nähtaval. Sport ja fännitegevus on oma olemuselt suuresti meelelahutuslikud, samas väga emotsionaalsed kultuurinähtused, milles on olulisel kohal huumor (vt nt Krikščiūnas 2020). Folkloorne nali on olnud elujõuliselt esil nt viimasel kümnendil Eesti spordis lahvatanud dopinguskandaalide rahvalikes reaktsioonides (vt nt Voolaid 2014; Laineste \& Voolaid 2020). Internetisuhtluses esineb nali tihti visuaalsete meemidena (vt Piata 2016: 41). Analüüsiosas järgime Limor Shifmani (2014) määratlust meemidest kui (post)modernsest folkloorist, mis väljendab ja kujundab ühiseid norme ja väärtusi kogukondades ja pärimusrühmades ning neist väljaspool (joonis 1).

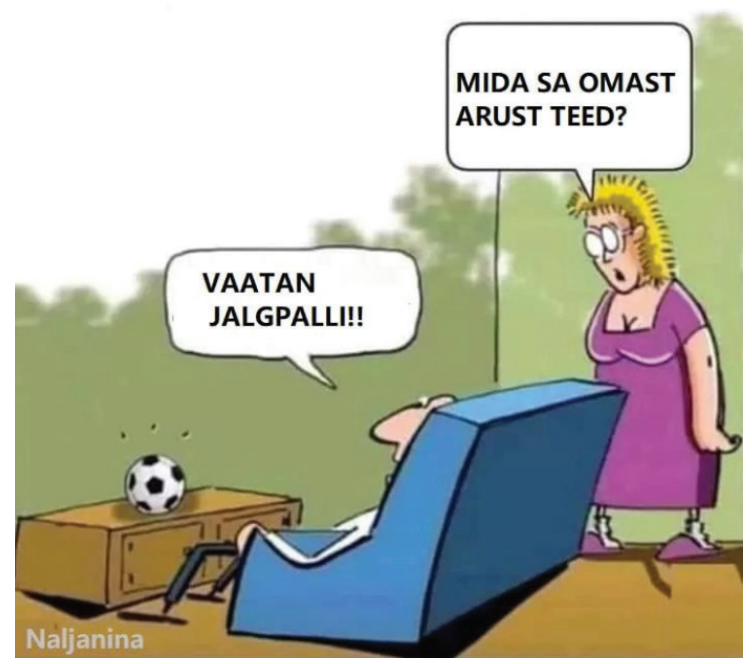

Joonis 1. Eriolukorra ajal levinud internetimeem väljendab tugitoolisportlaste keerukat olukorda spordivõistluste keelu ajal, mil jäi üle vaadata kodus ainult otseses mõttes jalgpalli (väljend jalgpalli vaatama on pigem kõnekeeles kasutusel metonü̈̈miliselt ja tähendab 'jalgpallivõistlusi, jalgpallivõistluste teleülekannet vaatama'). https: / / meeldib.com/mida-sa-oma-arust-teed/ (vaadatud 21.02.2021). 


\section{Sport Eestis ja Valgevenes pandeemia esimese laine ajal}

Sport ja fännikultuur olid Eesti koroonakriisis väga tähenduslikud, kuivõrd Terviseameti aruandes kinnitati, et esimese laine ajal koroonaviirusest enim räsitud maakonnas Saaremaal sõna otseses mõttes puhuti viirus laiali fännipasunatest $^{2}$ (Vinni 2020). Kultuuriliselt on huviväärne, et fännide poolt võistlustel puhutavate pasunate sobivus fännikultuuriga on olnud varem tõsine aruteluobjekt ja koroonakriis taaselustas nüüd selle diskussiooni. Jalgpallifännide seas levis kriitiline seisukoht, mida väljendas näiteks Nõmme Kalju fänniühenduse Roosad Pantrid Facebooki lehele tehtud postitus: "Pasunad on ühed jäledamad leiutised, mida iial tribüünidele toodud. Mitte ainult ei tapa nad vaimu, vaid nüüd ka inimesi. Ütle pasunatele EI, nagu seda tegi omal ajal Kalju, keelates Hiiul nende kasutamise. Tahad meeskonda toetada, tee seda eht-eestlaslikult lauluga. Ei taha laulda, plaksuta” (Roosad Pantrid 2020.) Saaremaa võistluste õppetunni järel on fännipasunad olnud edaspidi võistlustel keelatud (Karu 2020).

Spordiüritused ja nende hilisem ärajäämine koroonapandeemia ajal inspireeris mitmesuguse folkloori teket ja levikut (joonised 2 ja 3). Näiteks Saaremaal toimunud võrkpallivõistlus sai väga paljude meemide allikmaterjaliks. Uueks Saaremaa vanasõnaks nimetati irooniliselt Eesti Võrkpalli Liidu hüüdlause "Võrkpall on võrratu!"

Vaatamata raskele ajale said sportlased jätkata individuaal- ja videotreeningutega kõigis senistes huvirühmades (nii lastele, noortele kui ka esindusmeeskondadele).

Valgevenes oli olukord erinev. Tavapärane spordielu jätkus. Veelgi enam, Valgevene president Aleksandr Łukašenka kuulutas spordi üheks koroonaviiruse vastaseks ravimiks. Jäähallis hokimängu järel ajakirjanikule antud intervjuus väitis ta, et sport (ja eriti jäähoki) on parim viirusevastane ravim ning rõhutas, et ei näinud väljakul mingit viirust (OTV 2020). Kuigi Valgevene sportlased ei saanud osaleda rahvusvahelistel võistlustel, jätkusid kodumaised võistlused ja isegi pealtvaatajad olid staadionitele oodatud. Valgevene spordiüritustel polnud nii dramaatilisi järelmõjusid nagu Eestis Saaremaal, kuid mõnes populaarses jalgpalliklubis (nt FK Minsk ja FK Isloch) tuvastati siiski koroonaviiruse kolded. Valgevene spordisündmused ei köitnud mitte ainult kohalike, vaid ka teiste riikide spordisõprade tähelepanu (ka Eesti jalgpallifännid tunnistasid, et vaatasid Valgevene liiga mänge - vt nt Soccernet 2020). Valgevene spordi uudne olukord maailma spordiareenil kutsus esile uued fännireaktsioonid, mida enne koroonakriisi polnud keegi varem näinud. 


\section{VÕRKPALL ON VÕRRATU !} (saaremaa vanasõna)

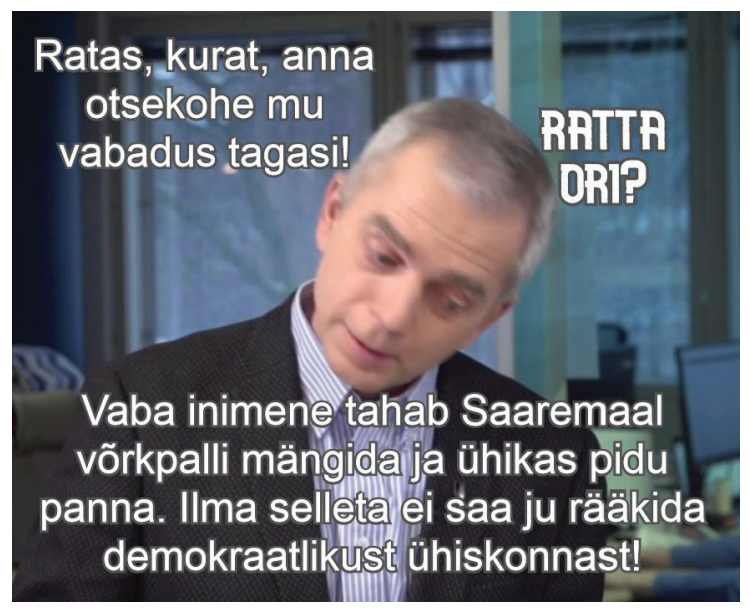

Joonis 2 ja joonis 3. 4. ja 5. märtsil Kuressaares toimunud võrkpallivõistluste mõjul internetis ringelnud meemid (https: / / www.facebook.com / 100013286351092 / posts / 887880004998203 ja https: / / uueduudised.ee/ arvamus / uhest-ideoloogiakulturnikust-ehk-jonnipunnajab-oma-oigust-taga/attachment/udu/, vaadatud 21.02.2021).

Üheks selliseks reaktsiooniks oli Valgevene meistriliigas mängiva jalgpallimeeskonna FK Slutsk auks rahvusvahelise fännigrupi loomine Facebookis. See sai nimeks FK Slutsk Worldwide ja selle asutasid Austraalia jalgpallifännid. Aja jooksul liitusid sellega paljude riikide jalgpallisõbrad, kellel polnud võimalust oma kodumaal jalgpallimänge vaadata. Grupi asutaja Shane Robinsoni sõnutsi toimus see internetis kihlveokontori kaudu: "Üks poistest [tema sõpradest] oli 
spordiennustuse lehel ja leidis selle Valgevene kõrgliiga, kus veel mängud käisid. Valisime just sel esimesel õhtul mänginud meeskonna, milleks oli Slutsk, ja sellest kõik algaski” (McCormack 2020). Oluline on mainida, et FK Slutski ingliskeelsete fännide üüratu tähelepanu juures mängis kindlasti tähtsat rolli klubi nimi ja selle ümber tekkiv homonüümne kalambuur. Kuigi Slutski linna nimi, mille järgi on ka klubi oma nime saanud, hääldatakse vene ja valgevene keeles [slu:tsk], sarnaneb selle kirjapilt ingliskeelse sõnaga "sluts" [slıts] (tõlkes 'lirvad, räpased eided'); ja nii võivadki keelelisi nüansse mitte tundvad inglise keele rääkijad eeldada, et klubi nime tuleb sarnaselt hääldada. Eeltoodud sarnasus meelitas klubi rahvusvahelise fännirühmaga Facebookis liituma nii mõnegi uue liikme ning inspireeris hulgaliselt huumori teket, millest tuleb juttu alapeatükis "Huumori tähtsus eriolukorraga toimetulekul".

\section{Allikad ja meetodid}

Võrdleva uurimuse aluseks on ühe ja sama pandeemia ajal erisuguste riiklike otsuste tõttu eri olukordadesse sattunud fännide tegevus. Valgevene uurimisallika moodustab Austraalia fännide algatusel 23. märtsil 2020 Slutski jalgpalliklubile Facebookis loodud leht FK Slutsk Worldwide. Tippajal enam kui 7000 liikmega grupis jagati regulaarselt meeme (kogutud 308 meemi), naljatati, aga ka arutleti jalgpalli ja koroonapandeemia üle, hoides kõrgel kogukonna vaimu ja toetades võistkonda. Rahvusvahelise liikmeskonna suhtluskeel oli põhiliselt inglise keel; isegi Valgevene grupi liikmed kasutasid tihti inglise keelt.

Eesti jalgpallifännide olukorda koroonakriisi platsimängudefitsiidi tingimustes analüüsime Premium liiga 2019 esinelikusse kuulunud jalgpalliklubide - Flora, Levadia, Nõmme Kalju ja Paide Linnameeskond - tegevuse põhjal sotsiaalmeedias. FC Flora FB-kogukonnal oli eriolukorra lõpus 17. mail 2020 umbes 15000 jälgijat, FCI Levadial 7000 jälgijat, Nõmme Kalju FC-1 17600 jälgijat, Paide Linnameeskonnal 5300 jälgijat. Kõigis gruppides tehti tavapärase sotsiaalmeedia turunduse raames päevas paar-kolm eestikeelset postitust, FCI Levadia postituste hulgas kohtab ka vene- ja ingliskeelseid. Jalgpall on Eestis viimastel aastatel üha rahvusvahelisem, nii tuli ka postituste järgsetes aruteludes ette vene- ja ingliskeelseid mõtteavaldusi.

Vaatlusalused Eesti lehed olid jalgpalliklubide ametlikud FB-lehed, Valgevene Slutski lehe aga lõid rahvusvahelised fännid. Andmete analüüs näitab, et mõlemal juhul oli kommunikatsioon ja initsiatiiv kahepoolne: jalgpallurid ja klubide administratsioon vajab auditooriumit ja fänne, kellele tegevus suunata; samas fännid vajavad klubi ehk meeskonda ja jalgpallureid, kellele poolehoidu näidata. 
Eesti klubide FB-fännirühmitused on küll mõnel klubil olemas, aga need on klubide endi FB-kogukondadest palju väiksemad. Nt Nõmme Kalju fännid on koondunud lehele Roosad Pantrid (https://www.facebook.com/pantrid, 720 jälgijat; Flora fännirühmitus on Flora Viies Sektor Ultras (https://www.facebook. com/FC-Flora-Viies-Sektor-Ultras-294946327186736, ainult 570 jälgijat), kuid võrreldes ametlike klubigruppidega on postitamine neis rühmitustes passiivsem ja üldiselt käib kogu kommunikatsioon klubi enda algatuse kaudu.

FK Slutski puhul ilmneb sotsiaalmeediavõrgustikus VKontakte (VK) sama tendents: ametlikul lehel on rohkem kui 7000 liiget, aga mitmetel fännilehtedel pole liikmeid rohkem kui sada. Samal ajal sai fännide loodud Facebooki grupp kiiresti populaarseks. Sellele aitasid suuresti kaasa nii ümbritsev reaalsus (kus Valgevene jäi peaaegu ainsaks maailma riigiks, kus profijalgpalliliigade mängud jätkusid) kui ka grupi sisuline pool, mida analüüsime allpool (vt kolm järgmist peatükki).

Eesti ja Valgevene valimite võrdlus seab ka teatud analüütilised piirangud. Eesti jalgpalliklubide fänniklubid on kohalike jalgpalliklubide enda looming. See tähendab, et Eesti jalgpalliklubid tegelevad kohapeal ka aktiivselt teadliku mainekujundamisega. Klubide ametlikud FB-lehed on sotsiaalmeedia sisuturunduse osa ja neid postitusi algatavad tavaliselt klubi avalike suhete osakond ja fännikoordinaatorid mitmesuguste väljakutsete ja kampaaniate vormis. Austraalias loodud rahvusvaheline fännklubi sündis aga spontaanse algatusena, mille taga oli üleüldine jalgpallivõistluste ärajäämine. Eesti jalgpalliklubide fännid on peamiselt kohalikud, Valgevene näites on suurem osa fänne inimesed, kes ei pruugi teadagi, kus Valgevene asub. See aga piirab teatud asjadest ja teemadest rääkimist oluliselt.

Meie peamine andmekogumise meetod on digitaalne etnograafia, mis hõlmab pikaajalist online-jälgimist. Analüüsiosas kasutame kogutud tekstide sisu ja üldiste iseärasuste kvalitatiivset analüüsi, sh kontekstianalüüsi.

Kogutud materjal (pildid ja kuvatõmmised) on tallel Eesti Kirjandusmuuseumi folkloristika osakonna teadusarhiivis EFITA (kataloog EFITA F37-001).

\section{Jalgpallifännide subkultuurid sotsiaalmeedias: ametliku klubitegevuse ja rohujuuretasandi vastasmõju}

Jalgpallifänne on pikka aega kontseptualiseeritud kui väljakujunenud subkultuuri (vt nt Carroll 1980; Hughson 1998; Richardson \& Turley 2006). Jalgpallifännide harjumuspärased kesksed tegevused - ühine mängude 
vaatamine pubis või staadionil, oma lemmikute ergutamine ja fänniriietuse kandmine - eeldavad neilt regulaarset silmast silma suhtlemist. Kuid massi-ja sotsiaalmeedia edenedes on populaarse klubi fänkonnad muutunud globaalseks ning paljud fännitegevused leiavad aset veebis. Tänapäeval on peaaegu võimatu olla aktiivne jalgpallifänn ilma online-fännitegevusteta (Ruddock et al. 2010: 325).

Peale klubide veebilehekülgede (mis keskenduvad peamiselt klubiga seotud teabe postitamisele ja millel pole nähtavaid tagasiside võimalusi) on olulisel kohal sotsiaalmeedia rühmad. Mõnda neist juhib klubide ametlik juhtkond, kuid paljudel jalgpalli tippklubidel on sotsiaalmeedias ka üks või mitu fännide juhitavat lehte ja gruppi, kus liikmed ise jagavad teavet oma lemmikklubi kohta ja suhtlevad (põhjalikum arutelu vt Rivers \& Ross 2019: 3). Niisugustel rühmadel on sageli ülemaailmne jälgijaskond, kes ei pruugi kunagi reaalelus kohtuda, ja nende ainus ühenduslüli on ühine toetus konkreetsele klubile.

Erinevalt tavapärasest meediapublikust saab igaüks veebipõhises osalusmeedias (Howard 2008) lisaks passiivsele tarbimisele ka ise aktiivselt sisu toota (Benigni et al. 2009). See osaluskultuuri aspekt (Jenkins 2006; Jenkins et al. 2018) muudab sotsiaalmeedia ka jalgpallifännidele atraktiivseks - ja lausa sõltuvust tekitavaks - suhtlusruumiks. Sarnaselt teiste valdkondade fännidega on jalgpallifännidel lisaks lemmikmeeskonna mängudele kaasa elamisest saadavale emotsioonile olulisel kohal mõttekaaslastega suhtlemine ja vestlemine, oma seisukohtade väljendamine päevakajalistel teemadel (nt konkreetsete mängijate või treenerite tegevus), eesootavate kohtumiste tulemuste ennustamine jne (Cleland \& Dixon 2015; Kossakowski \& Besta 2018). Nii ametlikesse kui ka fännide juhitavatesse sotsiaalmeediarühmadesse kuuluvatel fännidel on postitades-kommenteerides palju võimalusi oma klubile poolehoidu avaldada. Kõige populaarsemate ja tähelepanu äratavate tegevuste hulka kuulub visuaalsete ja audiovisuaalsete postituste tegemine.

Eriolukorra ajal korraldasid Eesti klubid fännidele mitmeid toetusüleskutseid ja osalusmänge. Uudses keerulises olukorras, millesse klubid kahtlemata sattusid, paluti fännidelt otsesõnu jätkamiseks rahalist toetust (nt Paide linnameeskonna kampaania "Jalgpall südames. Toeta Paide Linnameeskonda"). Ajutise kriisiaja täitmiseks korraldati rohkelt meelelahutusvõistlusi. Pakuti võimalust kordusena vaadata klubide varasemaid võidukaid mänge (nt Flora retroneljapäevad), korraldati mitmesuguseid turniire, millest oodati aktiivselt ja laialdaselt kõiki osa võtma. Aprillis toimus FCI Levadia sõprade pokkeriturniir, millest võtsid osa ka klubi juhtkonna esindajad, nt Sergei Pareiko; samuti korraldas pokkeriturniiri Nõmme Kalju, kaasates oma mängijad ja fännide rühmituse Roosad Pantrid: 
Kõikidel tahtjatel on võimalus ennast proovile panna Nõmme Kalju esindusmeeskonna mängijate ja pantrite vastu. Kas sina suudad anda meile sama hea lahingu kui meie sportlased väljakul ning Pantrid fännisektoris? (https://www.facebook.com/NommeKaljuFC/ph otos/a.117730824915358/3080154665339611/, 1. mai 2020, vaadatud 21.02.2021).

Korraldati kõikvõimalikke virtuaalseid väljakutseid. FC Flora postitas nn õige floraka bingo mängu, millel oli antud kasutajatele valik tegevustest, mida tehes saaksid fännid oma klubi mõtteliselt toetada (vt pilt 4). Nimetamist väärib ka sama klubi väljakutse "Flora liigub", kus klubi 60 töötajat külastasid virtuaalselt Premium Liiga staadione. Menukaks osutusid näiteks trikkide tegemise väljakutsed, nt FCI Levadia ISPORT CHALLENGE, mis kutsus üles jalgpallurite trikke järele tegema, neid lehel postitama ja vastavat teemaviidet täägima. Samasugust ideed kandis Paide Linnameeskonna kampaania "Saada trikk" üleskutsega saata klubile video mõnest vahvast trikist, vastutasuks pakuti võimalust “võita ägedaid auhindu!" (klubi fänniatribuutika - pusad jne). Kõiksugused trikinädalad olid populaarsed noormängijate hulgas, üksinda treenides sai sellega väga vahvalt meelt lahutada.

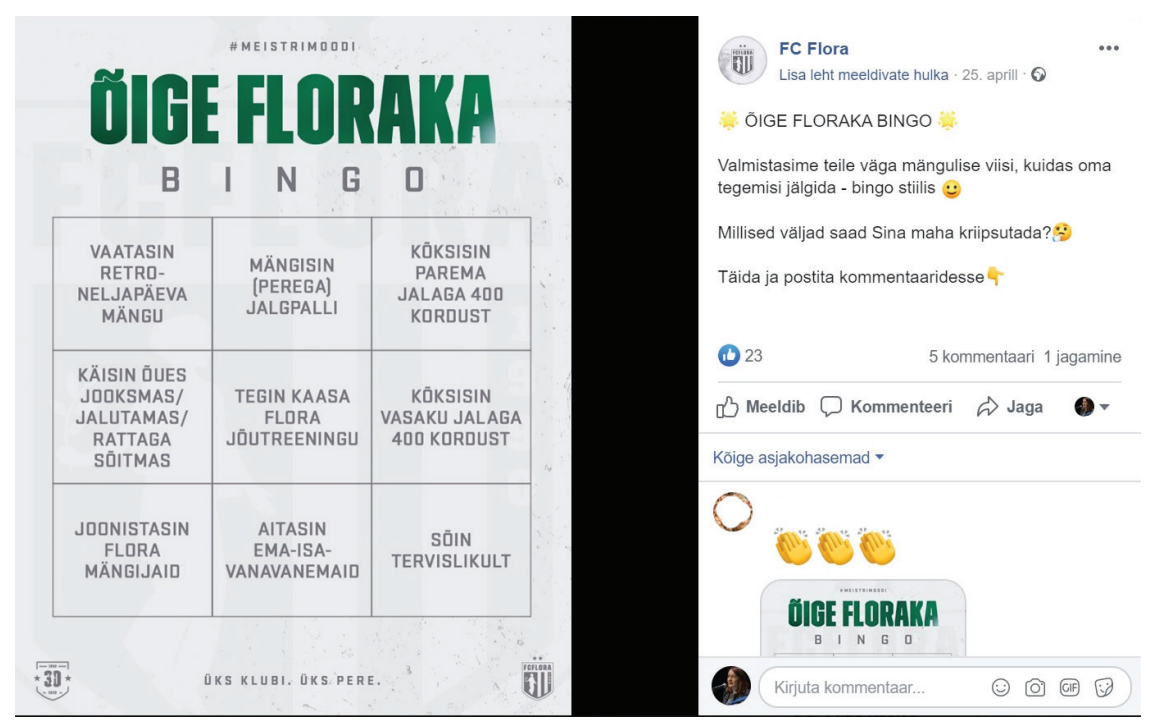

Joonis 4. FC Flora nn õige floraka bingo sisaldas nii klubiga seotud (retroneljapäevad, klubi mängijate joonistamine, klubi jõutreeningus osalemine) kui ka üldinimlikke tegevusi (lähedaste abistamine, tervislikult söömine, omaette treenimine). https: / / www.facebook. com / FCFlora / posts / 10158128593138389 (vaadatud 21.02.2021) 
Interaktiivselt kutsuti klubi poolehoidjaid näitama end klubi värvides; paluti kanda fännivarustust ja jagada sellest tehtud fotojäädvustusi klubi lehtedel. Rohket osavõttu pälvis FC Flora FB-lehe üleskutse kanda eriolukorra ajal hoolimata mängupõuast klubi värvides atribuutikat ja jagada pilte kaaslastega:

Mis oleks ilusam sellesse halli päeva, kui veidi rohelist 0 Saada ka oma pilt meile ja näita, et kannad rohevalget uhkusega seljas ja meeles! 엉 Q \#kannaflorat \#saamehakkama \#meistrimoodi (https://www.facebook. com/norman.poder/posts/2871237786277749)

Eesti klubidega võrreldes oli FK Slutsk Worldwide Facebooki lehel, mida fännid ise haldasid, enamus postitustest spontaansed. Sellel lehel oli kõige populaarsem formaat meemid (erinevalt Eesti klubide FB-gruppidest, kus internetimeeme üldiselt ei postitatud).

\section{ISLUTSK HERMANO,}

\section{YA ERES MEXICANO!}
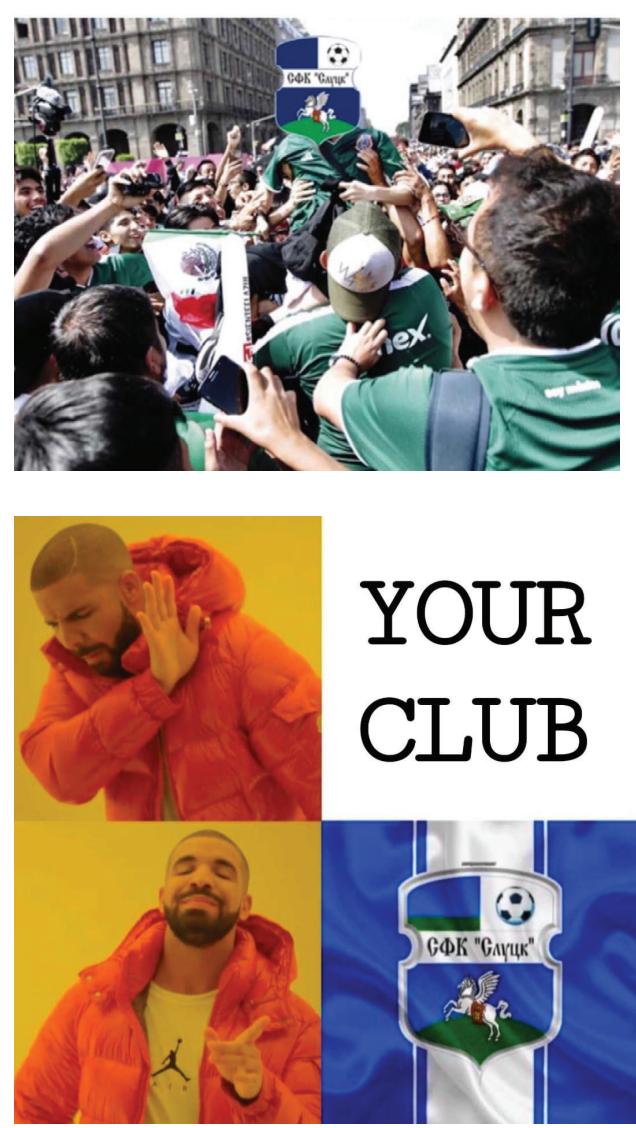

Joonis 5. Mehhiko fännid tegid FK Slutski toetamiseks meemi (https://www.facebook. com / photo. php?fbid $=725995238145400 \&$ se $t=g m .246998603148154 \&$ type $=3 \&$ theater $\& i$ $f g=1$ - vaadatud 21.02.2021).

Joonis 6. Pandeemia ajal eelistasid fännid FK Slutski oma klubi asemel. Meemis on kasutatud väga levinud malli tuntud Kanada räpparist ja näitlejast Drake'ist (https: / / www. facebook.com / photo.php?fbid=2996025063846 $982 \&$ set $=$ gm.246747433173271\& type $=3 \&$ thea ter\&ifg=1 - vaadatud 21.02.2021). 
Fännid lõid ka FK Slutski hümni, kusjuures ingliskeelse hümni looja oli FK Slutski fänn USAst. Hiljem, kui hümn võitis grupis populaarsust, tegid teiste riikide fännid sellest mitu versiooni, mida nad ka grupis postitasid ja mis põhjustasid elavat arutelu. Lisaks postitasid grupi liikmed ka joonistusi ja kleepse.

Joonis 7. USAs elav FK Slutski fänn lõi hümni (https://www.facebook.com / AndyBNY1 / videos / 10222390221402622 / ?sor ting_setting $=$ CHRONOLOGICAL - vaadatud 21.02.2021).

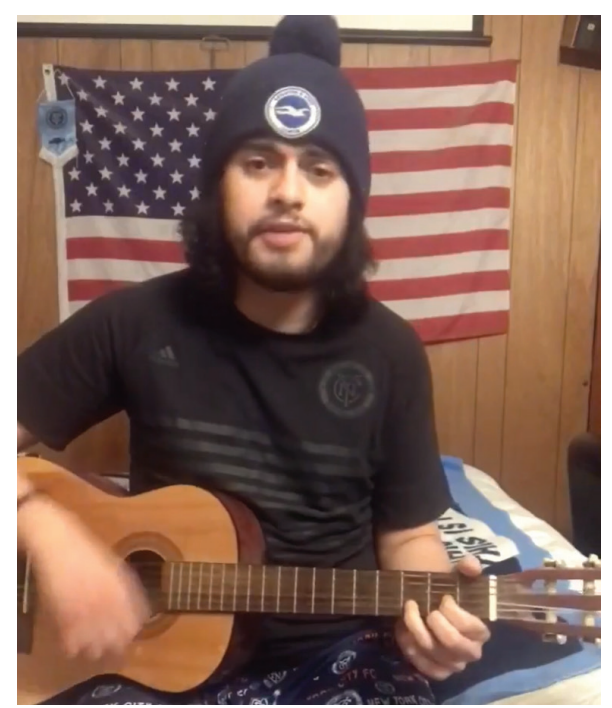

Nii nagu Eesti klubid, läksid ka FK Slutsk Worldwide fännigrupi liikmed kaasa lihtsate toetuskampaaniatega, mida pakkus FK Slutski ametlik PR-rühm. 7. aprillist pärineb näiteks üleskutse:

Tehke oma lemmikmeeskonna värvidega foto (fännikomplektid, sallid, lipud jne) ja postitage see teemaviitega \#weallloveslutsk Facebooki, Twitterisse või Instagrami. Kogume kõik fotod kokku ja avaldame need oma sotsiaalmeedias.

Täägige meie leht Instagramis @sfc.slutsk lugudes, postitame need uuesti enda lehele.

Järgmise kodumängu eel näitame fotosid suurel staadioniekraanil!

Fännikomplektid on kahtlemata üks jalgpallifänni kõige nähtavamaid atribuute, aidates tugevdada fännide kollektiivset identiteeti ja lisades nende kogemustele peaaegu pühaliku aspekti (Derbaix \& Decrop 2011). Uued FK Slutski fännid hakkasid seetõttu juba enne seda üleskutset saatma oma fotosid, täiendatuna klubi sümboolikaga. T-särke, klubi sümboolikaga salle, lippe ja muid klubikaupu, mida tavapärastes tingimustes saab hõlpsasti fännipoodidest osta 
või veebist tellida, polnud pandeemia ajal tarnehäirete tõttu kuigi lihtne kätte saada. FK Slutski rahvusvahelised fännid pakkusid sellele probleemile palju loomingulisi lahendusi. Esialgu täiendati oma riietust ja jalanõusid lihtsalt FK Slutski sümboolikaga (või vähemalt visuaalsete viidetega sellele). Enamasti valiti sinist tooni riideid (sinine on FK Slutski meeskonna värv), kuid üks toetajatest postitas endast selfi, seljas T-särk tekstiga "NSVL", ja lisas foto juurde kommentaari "Lähim asi, mis mul on Slutski komplekti juurde". Hiljem prooviti fänniriietust toota kodusel teel. Suurem osa sellest ei jõudnud küll kaugemale visuaalse kujunduse etapist ja sellega kaasnenud rühmasisesest arutelust, kuid mõndagi jõudis virtuaalsest ruumist pärisellu. Näiteks ühendas üks fännidest FK Slutski toetajate komplekti loominguliselt COVID-19 ennetamise teadlikkuse tõstmise kampaaniaga, postitades foto oma T-särgist, millele ta oli käsitsi kirjutanud: "FK SLUTSK SAYS: 1. wet, 2. soap, 3. wash. WASH YOUR HANDS." ('FK SLUTSK ÜTLEB: 1. vesi, 2. seep, 3. pesemine. PESE KÄSI', https://www.facebook.com/photo.php?fbid=10157663705643822 \&set=gm.252089199305761\&type=3\&theater\&ifg=1 - vaadatud 21.02.2021). Teised trükkisid oma T-särkidele ja kruusidele FK Slutski logo. Keegi joonistas enne mängu FK Slutski logo oma põsele. Lõpuks tegi üks fännidest kujunduse tekstiga "We All Love FK Slutsk" ja postitas selle platvormile Redbubble, mis võimaldab kasutajatel kataloogist endale tasu eest tellida ise disainitud fännitooteid (nt T-särke, magneteid, maske).

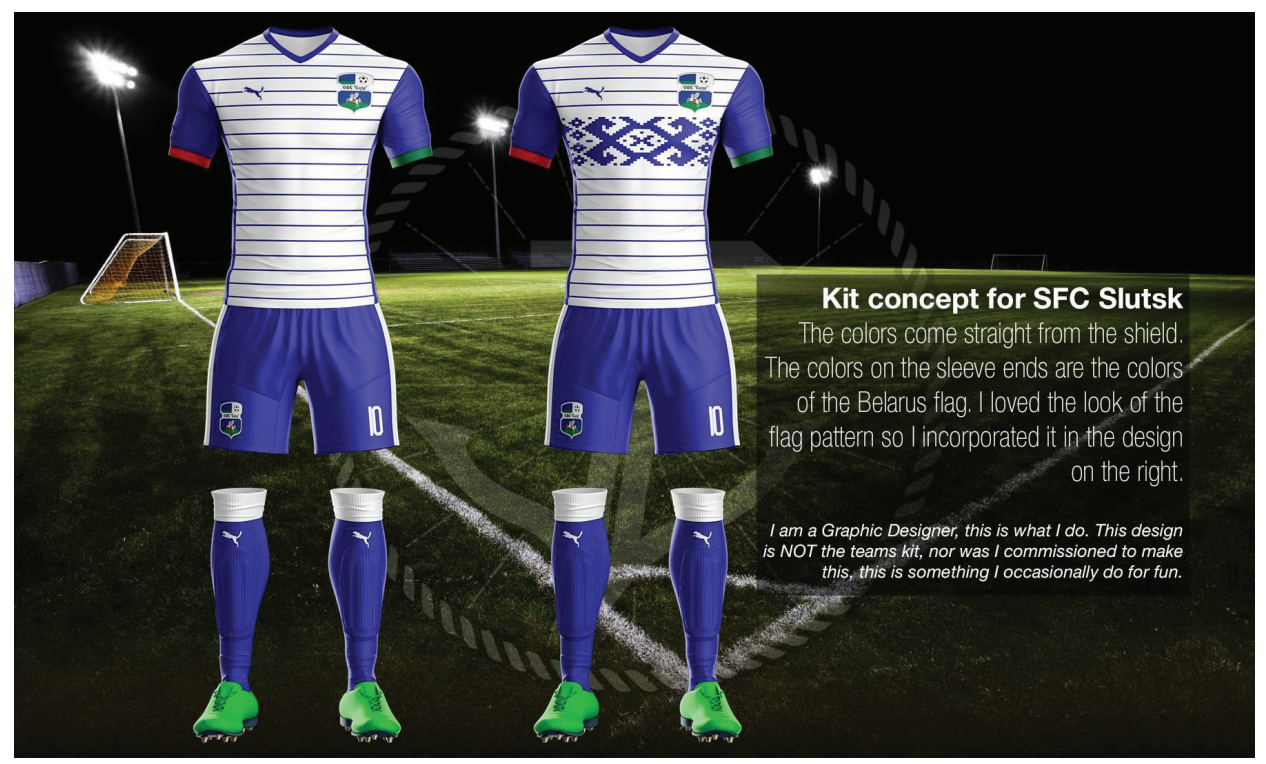

Joonis 8. Üks fännikomplekti idee (https: / / www.facebook.com / photo.php?fbid=3082386361 807132\&set=gm.250294209485260\&type=3\&theater\&ifg=1 -_vaadatud 21.02.2021). 


\section{Jalgpallurite suhtlemine fännidega}

Tavapärase arusaama järgi toimub suhtlus tuntud jalgpallurite ja fännide vahel ühepoolselt, seesugust kestvat suhet meediapersoonidega on nimetatud parasotsiaalseks. Donald Horton ja Richard Wohl kirjeldasid 1956. aasta artiklis massisuhtlusest ja parasotsiaalsest suhtlusest esimest korda nii parasotsiaalseid suhteid kui ka parasotsiaalseid interaktsioone. Nad kasutasid termineid mõnevõrra vaheldumisi, kuid keskendusid peamiselt meediatarbija illusioonile, mis tekib telesaadet vaadates või raadiosaadet kuulates, samal ajal meediategelastele kaasa elades või nendega samastudes (Horton \& Wohl 1956). Parasotsiaalset suhtlust spordikuulsustega saab võimendada, meelitades publikut ja luues positiivset hoiakut erinevatesse sportlaste identiteediga seotud elementidesse, nagu nende meeskond, reklaamitav kaubamärk jne (Spinda et al. 2009). Fännide ja spordikuulsuste parasotsiaalne suhtlus sotsiaalmeedias inspireerib fänne, eriti kui nad on ühiste huvidega veebikogukonna osa (Yuksel \& Labrecque 2016). Meie analüüs näitab, et veebisuhtlus ei kuulu spektri "silmast silma - parasotsiaalne" äärealale, vaid kätkeb kahepoolset kommunikatsiooni, sest jalgpallurid suhtlevad oma fännidega, eriti koroonaajal, kui suhtluskanalid on piiratud. Fännide ja sportlaste (para)sotsiaalse suhtluse analüüsimisel dünaamilise koosloome raames (vrd Sorokin 2018: 70) näitame, kuidas ühe ja sama eesmärgiga (oma võistkonna võidud) erinevate huvipoolte vastastikuses koostöös toimub pidev loomeprotsess.

Parasotsiaalne suhtlus toimus ka tavaolukorras, kui jalgpallurid hoidsid ise endaga seotud postitustel silma peal. Muidugi kestsid paljud tavaolukorras välja töötatud traditsioonid ka koroonaajal edasi, nt FB õnnesoovipostitustega peeti klubi sünnipäevalapsi - mängijaid, treenereid jt klubi olulisi liikmeid - meeles varemgi ja neile sooviti õnne ka eriolukorras. Samas said virtuaalõnnesoovid sünnipäevalapsele eriolukorras olulisemaks, sest kontakti puudumisel muud võimalused hällilast meeles pidada ju puudusid.

Eriolukorras said sportlastest sotsiaalmeedia kaudu arvamusliidrid ja eestkõnelejad, kes kutsusid fänne kehtestatud piiranguid järgima, kodus püsima, head eeskuju näitama, kodus treenima, et "see aeg üle elada" ja sellest tugevamana välja tulla (markeerides üleskutseid koroonakohaste teemaviidetega \#püsinkodus \#treeninkodus \#saamehakkama \#minuklubi). Postitusi oli võimalik kommenteerida ja spordikuulsustele tagasisiset anda (vt joonised 9 ja 10).

Näiteks paluti ennustada, kui pikalt olukord kestab ja millal taas mängida saab (vt joonis 11). Sellised ennustused olid kontrolli alt väljunud erakordses olukorras mõistetavad ja üldinimlikud, sellekohased arutelud olid üldiselt sagedased - nt millal taas maailm avaneb; millal üleüldse koroonaolukord lõpeb. 


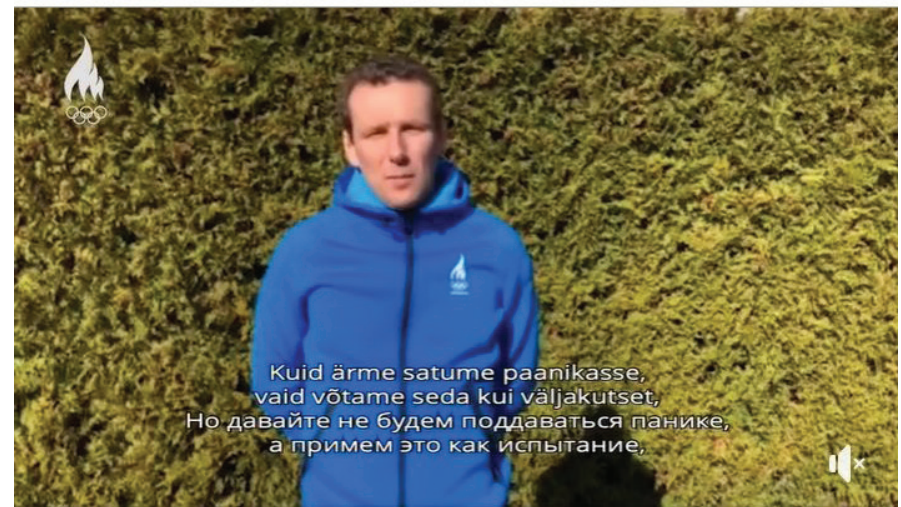

WWW.EOK.EE

\section{Konstantin Vassiljev \#püsinkodus \#treeninkodus}

Joonis 9. Tuntud jalgpallur Konstantin Vassiljev kutsus oma FBlehel üles täitma eriolukorra reegleid (https: / /www.facebook.com / Olympiafann /videos / 151881599413952 - vaadatud 21.02.2021).

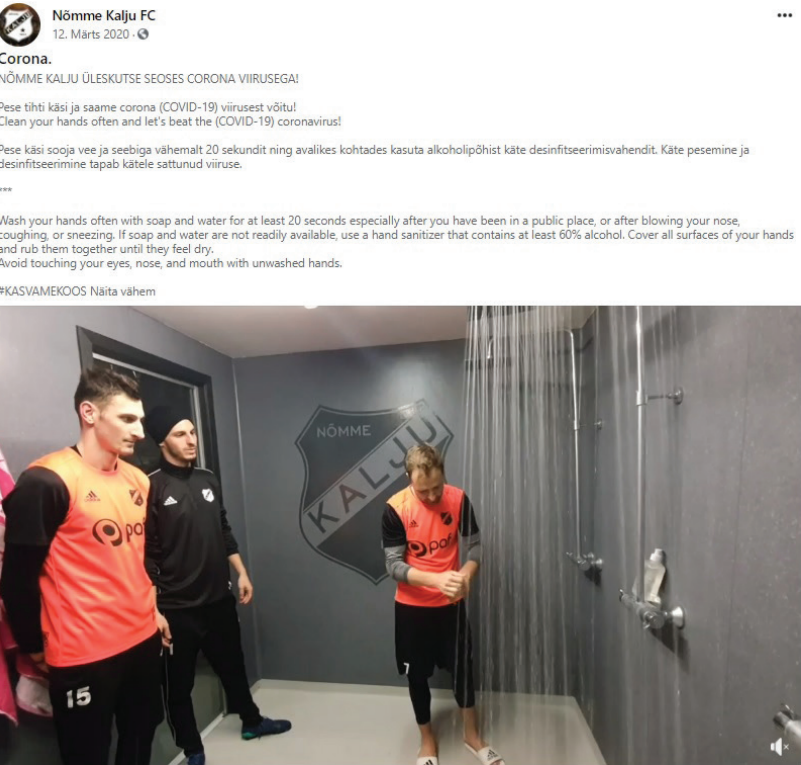

Joonis 10. Nõmme Kalju tegi kohe eriolukorra esimesel päeval mitmes keeles üleskutse käsi pesta vähemalt 20 sekundit. Mängijad näitasid duširuumis toimingu ette, postitusele reageeriti 59 korda ja seda jagati 17 korral (https: / / www.facebook.com / watch / ?v=210780329997554 - vaadatud 21.02.2021). 


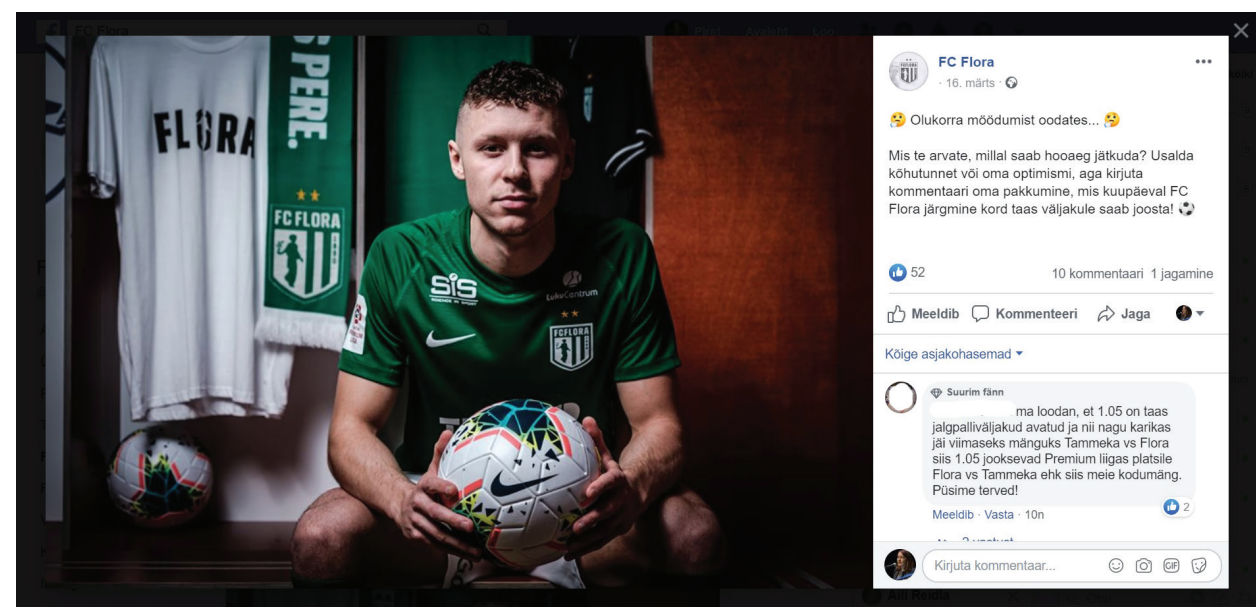

Joonis 11. FC Flora jalgpalluri Markus Poomi pildiga postituses kutsuti jälgijaid üles ennustama ja pakkuma aega, mil jalgpallihooaeg taas jätkub (https: / / www.facebook.com / FCFlora / posts / 10157978491418389 - vaadatud 21.02.2021).

FK Slutsk Worldwide gruppi tulvasid imetluse ja pühendumuse avaldused sageli märkimisväärselt ülevõimendatuna. Kuid erinevalt Euroopa suurtest klubidest ei säilitanud FK Slutsk "kaugete kuulsuste" staatust. Selle asemel alustas klubi juhtkond kiiresti dialoogi oma äsja leitud ülemaailmsete fännidega, postitades gruppi ja kommenteerides toetajate postitusi. On huvitav, et FK Slutski ametlik Facebooki leht loodi alles pärast seda, kui FK Slutsk Worldwide hakkas populaarsust koguma; selle grupi postitused on peaaegu eranditult ingliskeelsed (erinevalt nende pikaajalisest venekeelsest rühmitusest VK-s, mis on suunatud kohalikele toetajatele). FK Slutski PR-meeskond on mõne mängijaga korraldanud küsimuste ja vastuste sessioone, paludes rahvusvahelistel toetajatel esitada oma küsimused ja seejärel voogesitanud nende vastuseid Facebookis.

Ka mängijad ise suhtlevad vaatamata keelebarjäärile ja ajavahele oma rahvusvaheliste fännidega otse, kasutades seejuures ka huumorit. Ründaja Artem Serdyuk, kellest sai klubi rahvusvaheliste fännide seas üks populaarsemaid mängijaid, vastab sageli fännide postitustele, kus temast juttu. Kui üks fännidest postitas lühikese videoklipi, kus Serdyuk mänguks valmistus, pealkirjaga "Artem doing his impression of Let's Twist Again...", vastas Serdyuk: "dancing dancing ordered? (2) viidates selliselt rahvusvahelise fännikogukonna nõudmisele, et klubi võtaks kasutusele oma originaalse tähistamise, millega ära märkida iga klubi poolt löödud värav. Värava tähistamise nali ulatus ka veebisuhtlusest kaugemale. Kui üks fänn esitas FB-grupis "värava tähistamise 
väljakutse”, siis järgmise matši ajal sooritasidki FK Slutski mängijad tänuks oma Austraalia fännidele ja nende tunnustuseks väravatähistuse "känguru stiilis".

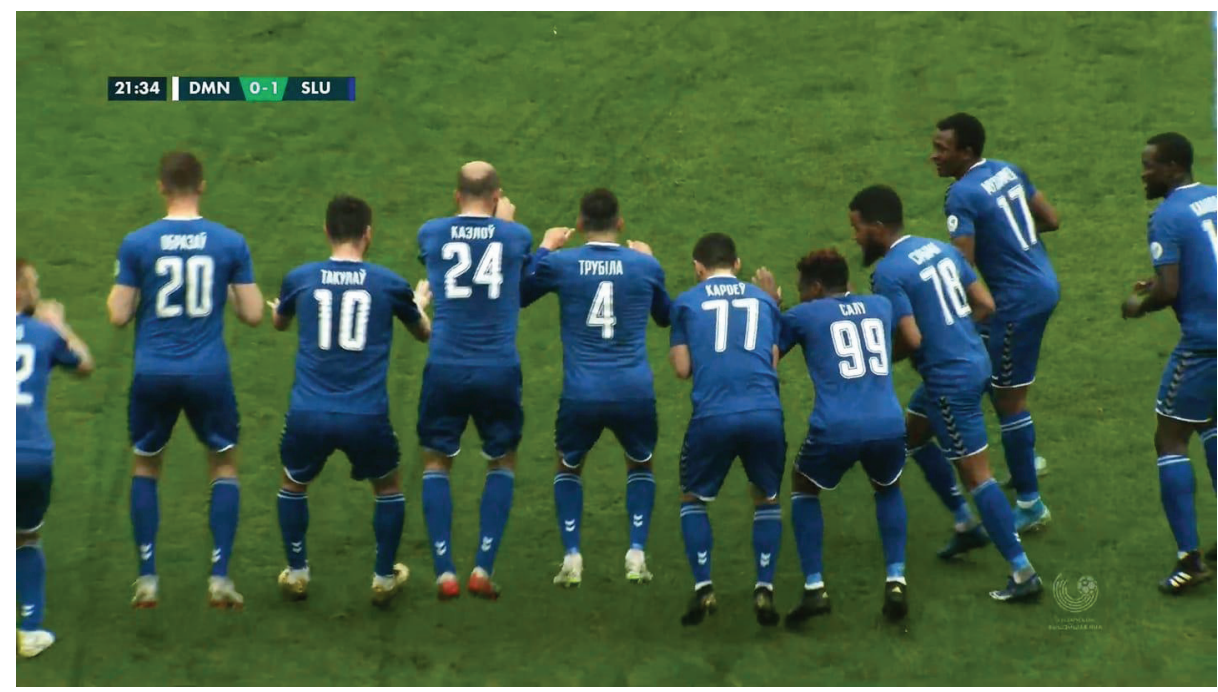

Joonis 12. "Känguru värava tähistamine" (https://www.facebook.com/photo.php?fbid=1021 $7045888441246 \&$ set $=$ gm.269837757530905\&type $=3 \&$ theater\&ifg=1 - vaadatud 21.02.2021).

Kuigi Eestis olid võistlustes katkestused, jätkasid sportlased treeningutega, tehes seda isolatsioonis suuresti omal vastutusel. Virtuaalselt oli treeneritel võimalik treeninguid kaugjuhtida ning digitehnoloogia ja nutiseadmed võimaldasid sidet pidada ja kogukonnatunnet säilitada. Loomulikult anti sellistest isolatsiooni- ja karantiinitreeningutest ka klubi FB-lehtedel laiemale üldsusele teada (vt joonised 13 ja 14) ja neile oli võimalik kaasa elada, ise kaasa treenida. Ka jalgpalliajakirjanikud, kes uudses olukorras kaotasid tavapärase töö - otsereportaažide tegemise võimaluse - häälestusid ümber ja keskendusid sportlaste individuaalsele hakkamasaamisele koroonaga seotud eriolukorras (vt nt Voolaid 2020b).

Populaarseks kujunesid otse-eetris videotreeningud esindusvõistkondade mängijate juhendamisel.

5. mail palus Eesti Jalgpalli Liit valitsuselt luba meistriliiga mängudega 19. mail taas alustada. Esialgu võisteldi ilma publikuta ja nõuetekohaste piirangutega. Fännid ei saanud küll oma klubi esindusmeeskonda staadionil toetada, kuid kiiresti leiti alternatiivseid võimalusi. Nt 23. mail tegi Nõmme Kalju ametlikul FB-lehel postituse: 
Olenemata sellest et tribüünid peavad olema tühjad on rahvas kogunenud lisaks tv ülekandele ka Hiiu staadioni kõrvale männi metsa pikniku korvid kaasa 0

Kuid see mäng ei toimu vaikuses vaid fännide jaoks on Event Center helindanud staadioni ning loonud helisilla meeskonna ja tema fännide vahel ... Respect!

\#NKFC \#MINUKLUBI \#NÕMMEKALJU \#KASVAMEKOOS \# $E V E N T C E N T E R$ ” ( h t t p s : / / w w w. f a c e book . c o m / watch/?v=253393715869395 - vaadatud 19.02.2021).

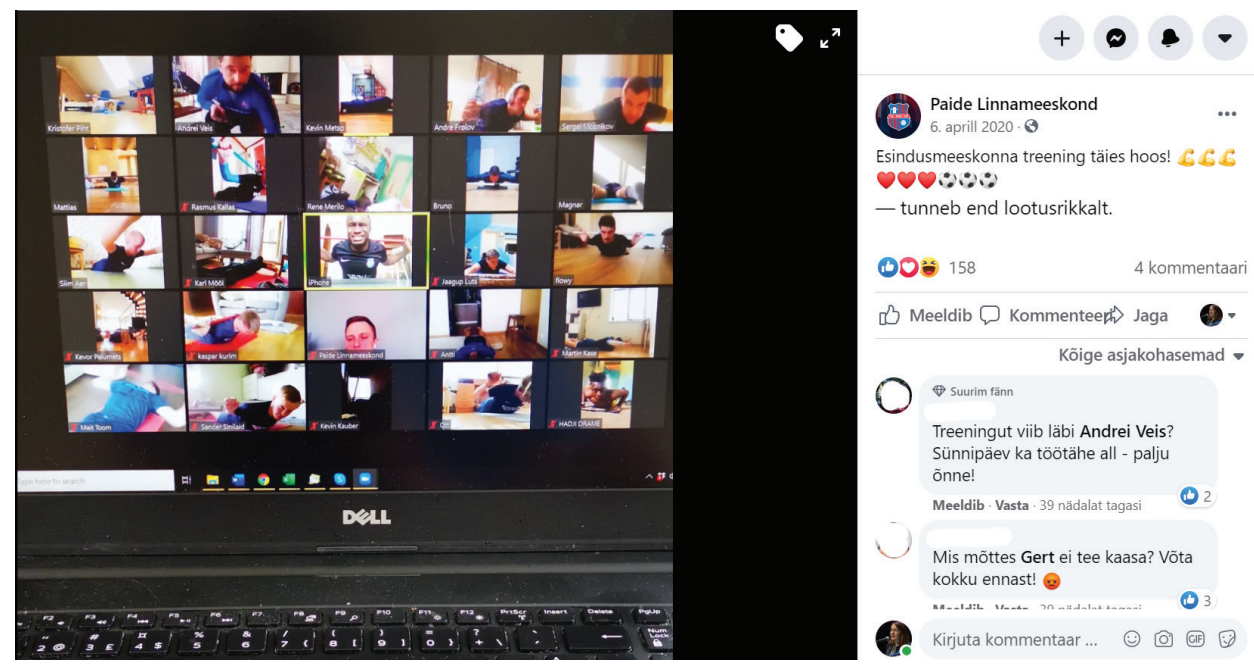

Joonis 13. Paide Linnameeskonna postitus - arvutiekraani foto esindusmeeskonna isolatsioonitreeningu ajal (https://www.facebook.com/PaideLinnameeskond/photos /a.746381475380806/3098849300134000 - vaadatud 21.02.2021).
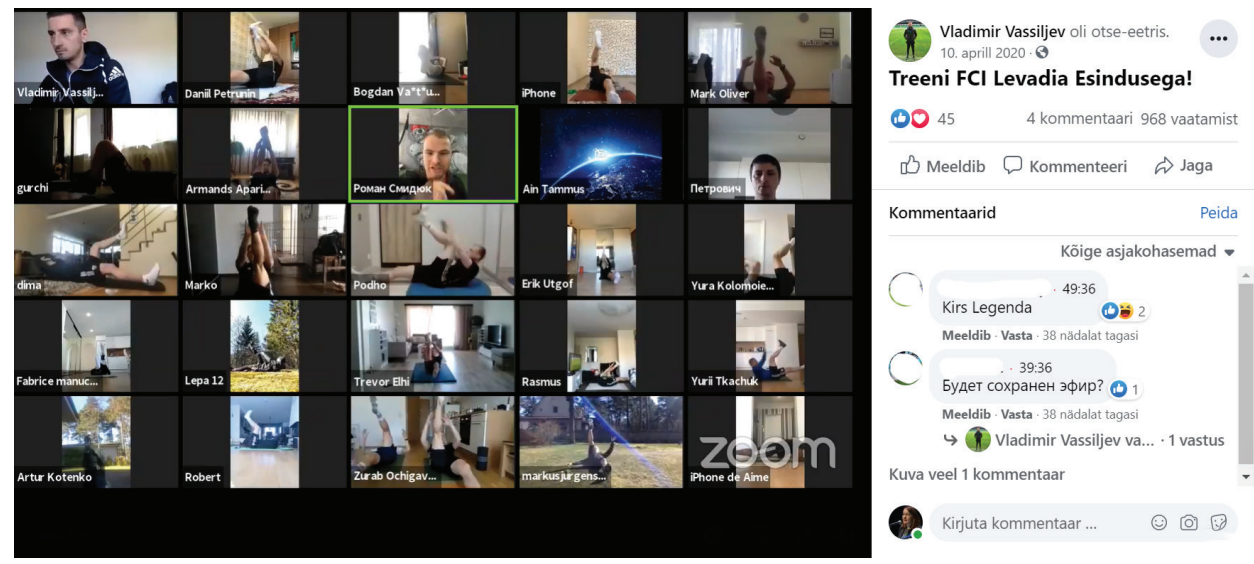

Joonis 14. FCI Levadia esindusmeeskonna otse-eetri videotreening toimus vene keeles (https: / / www.facebook.com/vovkjn/videos /3045506495488686 - vaadatud 21.02.2021). 
Pärast eriolukorraaegset mängupõuda leiti erinevaid võimalusi kogunemiseks väljaspool staadioni, olgu vabas õhus või ka tiheda õlgõlatundega pubides. Viimatimainitud tõsiasi - kogunemised siseruumides - muudab aga ametlike piirangute kasu omakorda küsitavaks. Publik lubati tribüünidele taas 1. juulil.

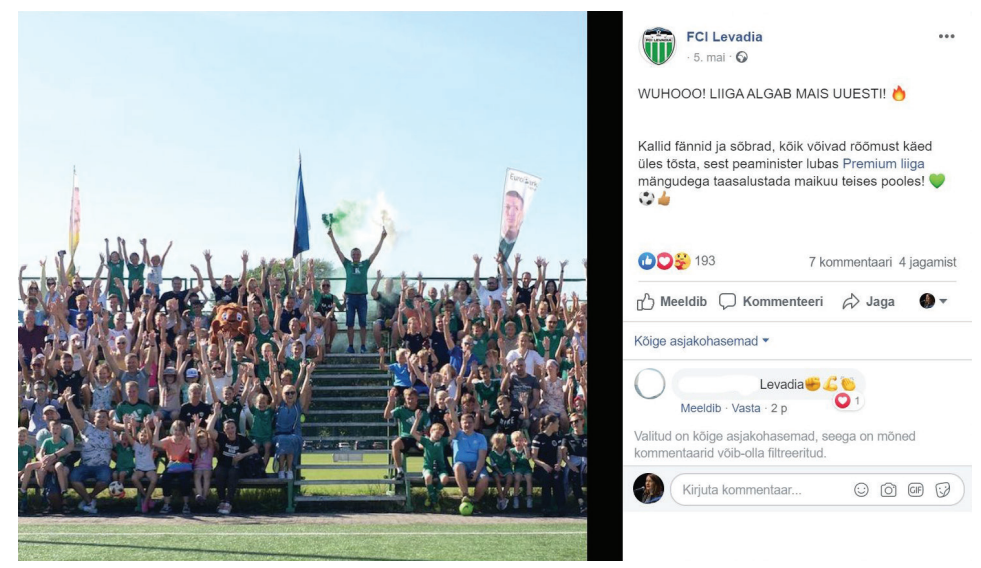

Joonis 15. Mai algul saabus teade mängude alustamise kohta 19. mail, info levis sotsiaalmeedias kulutulena ning võeti vastu nn rõõmuhõisetega (FCI Levadia postitus, milles kasutati varasemat fotot staadionil juubeldavatest fännidest) (https: / / www.facebook.com/fcilevadia/photos /a.624426940958426/3074366732631089/ - vaadatud 21.02.2021).

FK Slutsk Worldwide grupi välismaalastest liikmed aga ei saanudki oma nn lemmikklubi FK Slutski staadionil toetada, isegi mitte pärast koroonaviiruse esimese laine lõppu. Kui maailm suvel mõnevõrra taasavanes, jätkati ka mujal riikides taas jalgpallimängudega ja suurem huvi grupi tegemiste vastu vaibus. Mõned grupi liikmed lõpetasid selle aktiivse jälgimise, mõned lahkusid grupist. Paljud jätkasid FK Slutski jälgimist ja postitusi Facebooki grupis (enamasti mängupäevadel), avaldades rõõmu, kui klubi skooris või võitis, ja elasid aruteludes välja oma kaotusekibedust.

\section{Huumori tähtsus eriolukorraga toimetulekul}

Huumor on spordimaailma loomulik väljendusvahend (Krikščiūnas 2020: 243). Huumori tähtsust keerulises koroonaolukorras ei saa alahinnata, kuna sellest kujunes üks positiivseid toimetulekustrateegiaid. Huumori kasutamine sellises 
suhtlemises muudab kogemuse veelgi suuremaks, saades veebikogukonna kaasliikmetelt positiivse vastuse (Kytölä 2012: 239).

Keelemäng ja kalambuur oli üks naljatamise populaarsemaid vorme. Eespool oli jutuks sõnamäng FK Slutski nimega, mis ingliskeelsetele fännidele nalja tegi. Kuid nimi "Slutsk" võib tekitada jalgpallisõpradele ka muid seoseid. Siin tuleb mängu näiteks tuntud jalgpallitreener, endine Venemaa koondise ja mitmete kuulsate jalgpalliklubide peatreener Leonid Slutsky. Rahvusvahelised FK Slutski fännid soovitasid Slutsky kaasata klubi juhtimisse, tootes seejuures taas nimede sarnasusel tuginevat humoorikat pildimaterjali (joonis 16).

Joonis 16. Sluts-Slutsk-Slutsky keelemäng kajastus ka humoorikal internetimeemil (https: / / www.facebook.com / photo.php?fbid=2680292968 $748256 \&$ set $=$ gm. 259305608 $584120 \&$ type $=3 \&$ theater $\& i$ fg=1 - vaadatud 19.02.2021).

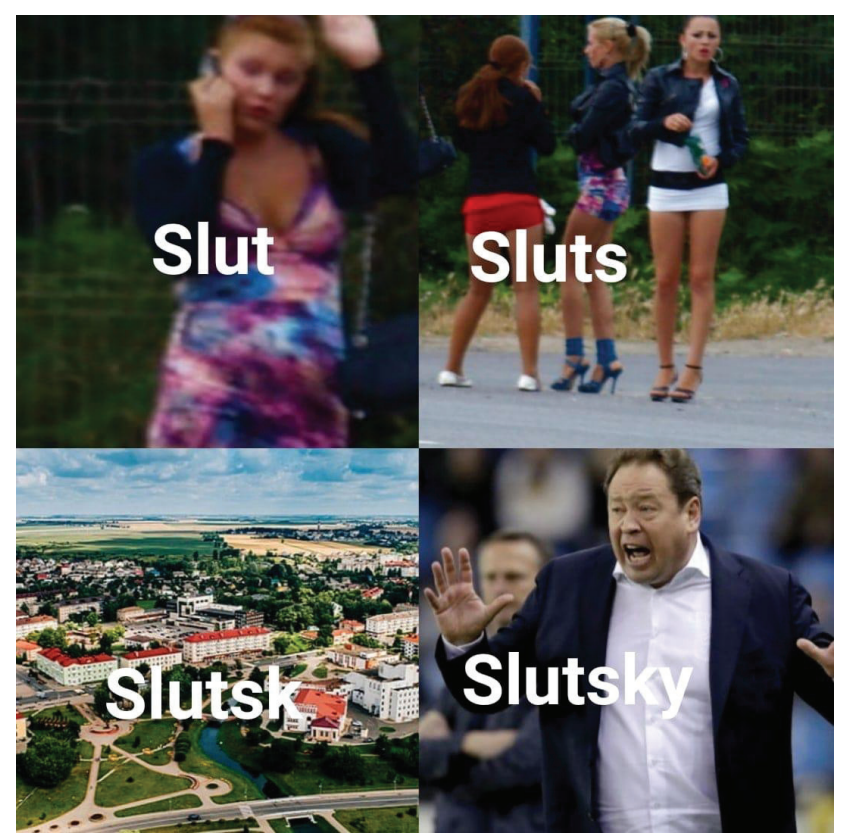

Keelemäng oli ka Eesti Facebooki postitustes tähtsal kohal. Näiteks aprilli lõpus naljatasid Eesti klubid postitustega, milles esitati kogu meeskonna nimed anagrammides. Huumor tekkis sellest, et välja pakutud nimed olid tähendusega sõnad (joonis 17). Kontekstilise info korras on oluline mainida, et kahtlemata saadi anagrammimänguks inspiratsiooni samal ajal TV3 kanalil väldanud populaarsest telesaatest "Maskis laulja”. Nimelt oli saatejuht Mart Sander kaks päeva enne anagrammide postitust, 26. aprilli saates üllatanud vaatajaid rahvusvahelise anagrammide päeva puhul lustlike sõnamängudega, koostades anagramme saate ja žüriisse kuulunud detektiivide nimedest. 


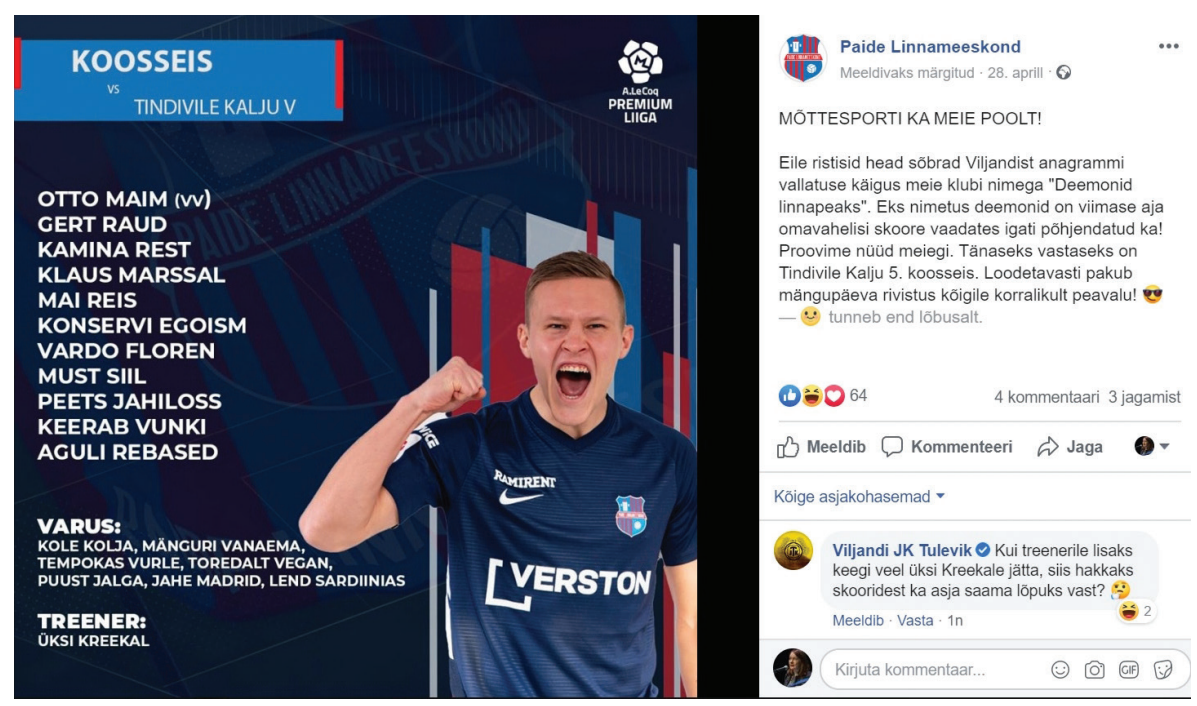

Joonis 17. Paide Linnameeskonna humoorikas postitus, milles mängijate koosseis esitati anagrammidena (https://www.facebook.com/PaideLinnameeskond/photos /a.178865855465707/3151666098185653 / - vaadatud 21.02.2021).

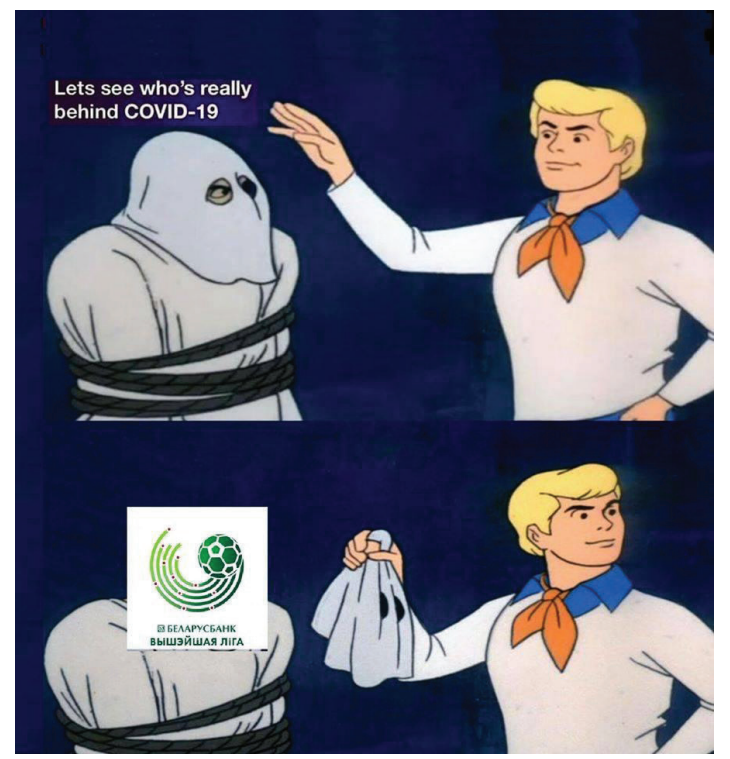

Joonis 18. Internetimeemis pandeemia ja Valgevene kõrgliiga kohta vihjatakse sellele, et tegelikult on pandeemia puhkemise taga Valgevene jalgpalli kõrgliiga (https: / / www.facebook.com/photo.php?fbid=10163227184135052\&set=gm.2480 08343047180\&type=3\& theater\&ifg=1 - vaadatud 21.02.2021). 
Mõned naljad olid COVID-19 pandeemiaga otsesõnu seotud. FK Slutsk Worldwide rühmas viitasid mõned postitused Valgevene presidendi (humoorikale) ettepanekule, et viin ja saun võivad aidata ära hoida koroonaviiruse levikut. Valgevene jalgpalliliigade teistest erinev otsus jätkata pandeemia ajal mängimist ei pääsenud samuti grupi liikmete tähelepanust. Fännid pakkusid isegi naljaga pooleks, et Valgevene kõrgliiga korraldas pandeemia, et pälvida kogu maailma jalgpallisõprade tähelepanu (joonis 18). Kogu pandeemia vältel levisid rohked vandenõuteooriad kurja viiruse päritolu kohta (Hiiemäe et al. 2020: 1014; Kuperjanov 2020), mistõttu niisugust tõlgendust saab pidada ka vandenõuteooriate paroodiaks.

Hoolimata asjaolust, et FK Slutski erakordne rahvusvaheline toetajaskond sündis suuresti tänu COVID-19 puhangule, ei ole koroonahuumor iseenesest sellise rahvusvahelise Facebooki grupi menu taga. See on eriti silmatorkav, kuna palju pandeemiaga seotud huumorit, sh internetimeeme ja muus vormis nalju, levis sotsiaalmeedias just 2020. aasta kevadel (Fiadotava 2021). Enamik FK Slutsk Worldwide grupi humoorikaid viiteid COVID-19-le pärinevad märtsi lõpust ja aprilli algusest, mil Valgevene kõrgliiga jätkamine viiruse jätkuvast levikust hoolimata oli eriti silmatorkav. Mais ja juunis näitas viiruse levik Euroopas vaibumise märke, tasapisi alustati mängudega ka teiste riikide jalgpalliliigades ning teema vastu kadus huvi. Selle asemel algasid tõsised ja murelikud arutelud, kui mitme teise Valgevene klubi mängijad andsid positiivse COVID-19 testi. Võib spekuleerida, et kuna Slutski mängijate oht koronaviirusesse nakatuda muutus üha reaalsemaks ja psühholoogiliselt vähem kaugemaks, muutus normi rikkumine - kui kasutada Peter McGraw ja Caleb Warreni teooriat (2010) - vähem healoomuliseks ja seega vähem huumorit õhutavaks. Võib olla ka teine põhjus, miks koroonaviirusega seotud huumor ei saanud FK Slutsk Worldwide Facebooki grupis populaarseks. Nagu varem mainitud, loodi grupp selleks, et kompenseerida jalgpallitegevuse puudumist teistes liigades ja aidata jalgpallisõpradel pandeemia ajal kohaneda maailma uue reaalsusega. Seetõttu sai grupist kanal reaalsusest pääsemiseks ja pandeemia põhjustatud hirmude ja ebakindluse peatamiseks. Tavaliste fänniarutelude ja veebitegevuste kaudu suutsid grupi liikmed end üleküllastunud COVID-19 teema eest kaitsta ja isegi viirusega otseselt seotud huumorit, mida paljudel teistel sotsiaalmeedialehtedel levis ohtralt, ei sattunud sellele mängumaale liiga tihti. Teisisõnu: kuigi Slutski postitused olid meelelahutuslikud, ei esinenud neis viirusega seotud nalju.

Ka Eesti klubide FB-gruppides oli nali omal kohal, kuid siingi ei keerelnud naljad otse COVID-19 ümber (klubi ametlik FB-leht ei saagi endale koroonanalju lubada, kuivõrd see on liiga tundlik teema), vaid pakkusid mõnusat huumorit muudel, sh jalgpalli endaga seotud teemadel. 
Näiteks Eestis ei saanud füüsilistel spordivõistlustel osaleda, mistõttu imiteeriti augutäiteks mitmeid mänge virtuaalmaailmas. Paide Linnameeskonna intervjuude sarjas “Jalgpall südames” võrdles Paide linnapea Priit Värk jalgpalli strateegilise malemänguga ja asetas esindusmeeskonna võtmemängijad malenuppude rollidesse (vt joonis 19). Humoorikas postitus põhjustas elevust ja leidis rõõmustava vastuvõtu, kuid linnapea teguviis viitas ka jalgpallile kui kohaliku enesemääratlemise seisukohast olulisele atribuudile. Fotol esineb linnapea Paide Linnameeskonna salliga, millega samastab end ilmselgelt oma koduklubi fännidega.

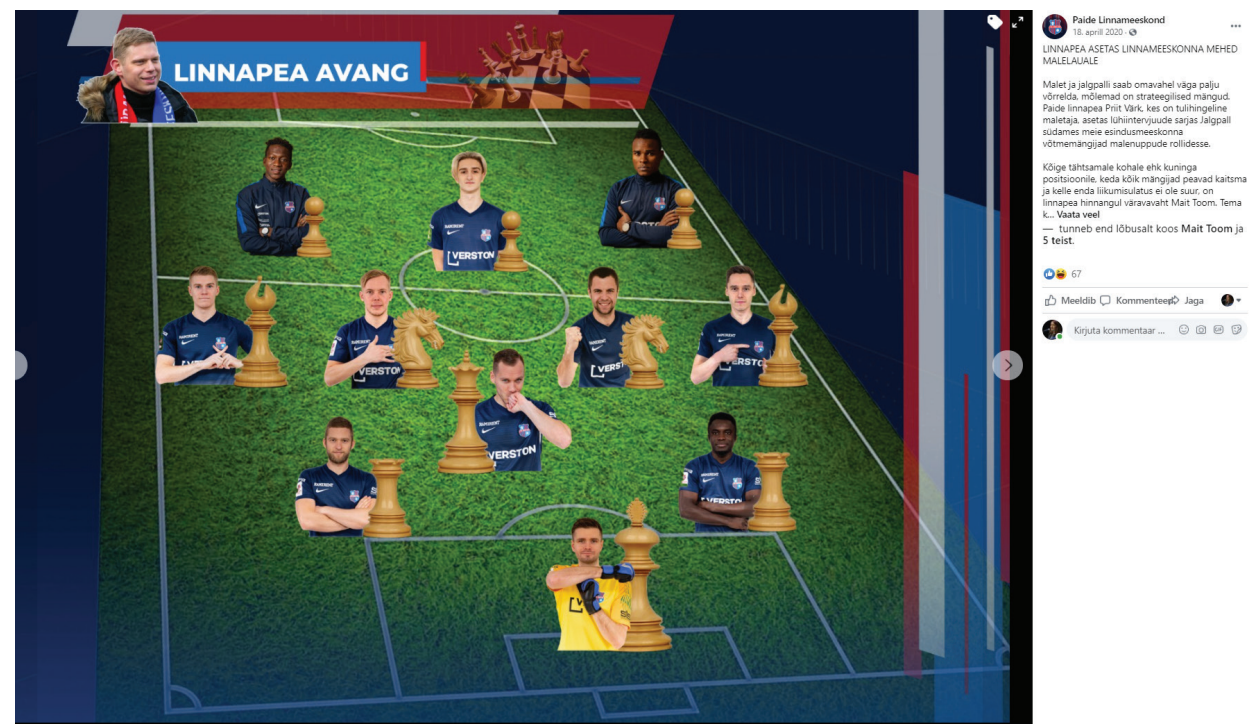

Joonis 19. Paide Linnameeskonna meeleolukas postitus "Linnapea avang", milles Paide linnapea esitas esindusmeeskonna võtmemängijad malenuppudena (https: / /www. facebook.com/PaideLinnameeskond/photos/a.178865855465707/3127988997220030 vaadatud 21.02.2021).

Eesti klubid tegid samuti humoorikaid algatusi, nt 3. aprillil köitis vaatajaid Paide Linnameeskond videopostitusega erioperatsioonist "pensionipäev". Nimelt hoidis pensionipäeval, mil poes käib tavalisest rohkem külastajaid, klubi noortetreener Roman Zarovski klubi koostööpartneri COOP Järva kaupluse juures silma peal, et inimesed hoiaksid ohutut kaugust ja peaksid kinni 2+2 reeglist (joonis 20 ja videopostitus: https://www.facebook.com/ PaideLinnameeskond/videos/898812833912231 - vaadatud 21.02.2021). 


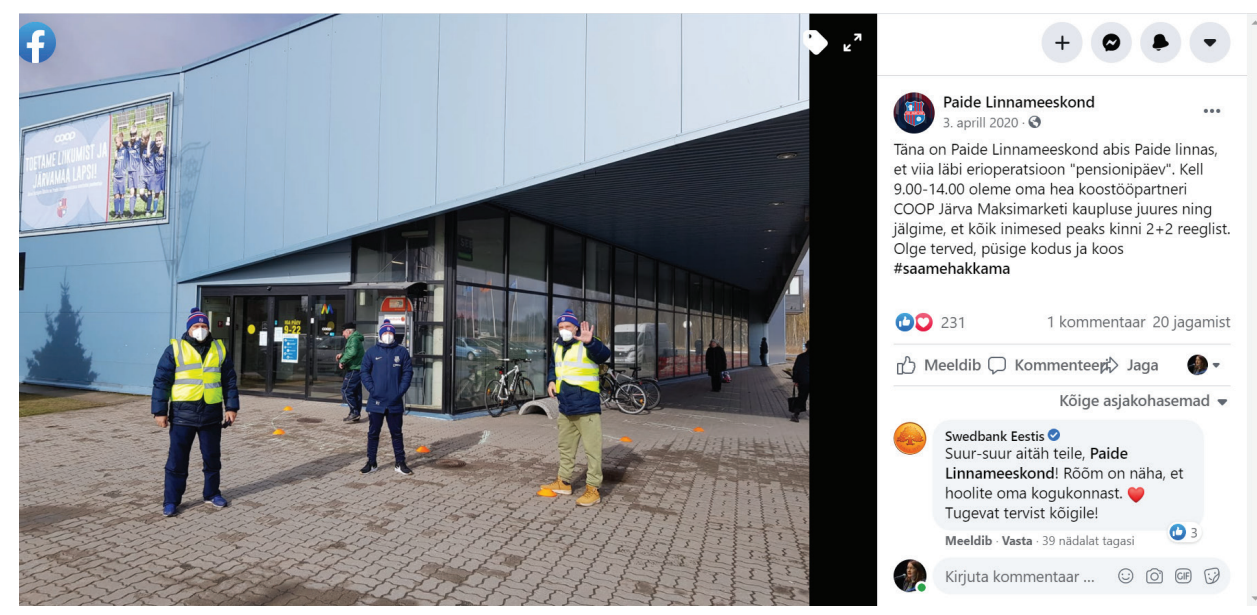

Joonis 20. Paide Linnameeskonna noortetreenerid COOP Järva kaupluse juures patrullimas, et kõik külastajad distantsi hoiaksid (https: / / www.facebook.com / PaideLinnameeskond/ph otos /a.746381475380806/3091447644207499/ - vaadatud 21.02.2021).

Mängupausi ajal levisid meelelahutuslikud videoklipid sellest, mida teevad karantiiniolukorras Premium liiga klubide maskotid. FCI Levadia tegi mitu lustlikku videopostitust armastatud maskoti Leffu tegemistest tavapäratul üksinduse ajal (nt hoidis ta staadionit korras, lõikas kääridega muru, korraldas endale sportlikke jalgpallivõistlusi ja tegi trikke). Samaväärsed olid Nõmme Kalju postitused sellest, kuidas maskott Roosa Panter "teeb kodus pulli" (6. aprill).

FK Slutsk Worldwide grupis tunnistasid paljud liikmed erilisi asjaolusid, mis on muidu silmapaistmatu meeskonna intensiivse rahvusvahelise tuntuse kogumise taga. Toodeti mitmesuguseid meeme, nalju ja muudki humoorikat, mis kinnitasid fännide liialdatud lojaalsust oma uue lemmikklubi vastu. FK Slutsk Worldwide grupi teemad ja huumoriliigid ei tulenenud üksnes fänluse objektist, vaid ka keskkonnast, kus see fänlus levis, ja sotsiaalse suhtluse olemusest selles. Ehkki grupi eksistentsi alguses oli fännide ja jalgpallurite suhtlus parasotsiaalne, liitusid FK Slutski mängijad ja mänedžerid varsti grupiga ning suhted muutusid sotsiaalseteks. Audiovisuaalse huumori levimus rühmas peegeldab rahvahuumori kasutamise üldist suundumust (Laineste 2016), eriti sotsiaalmeedias (Weitz 2017: 2). Rühma lühike ajalugu seadis teatud piirangud ka huumori sisule: kuna liikmetel ei olnud palju ühiseid kogemusi ega väljakujunenud siduvaid nalju, loodi suurem osa huumorist viisil, mis muudaks selle kõigile liikmetele hõlpsasti mõistetavaks ega vajaks palju kontekstuaalset teadmist (vrd Adetunji 2013: 159 pikaajalise fänni metafoorselt kodeeritud 
tögamise kohta). Aja jooksul arenesid mõned rühma naljad siiski selle liikmete jaoks kohalikeks meemideks (vt joonis 21). Nende struktuur aitas kaasa ka meemide kontseptualiseerimisele. Paljudes meemides kasutati populaarseid ülemaailmseid meemimalle, kuid neile lisati FK Slutskile viitavad pealdised (globaalsete meemide kohalike muganduste kohta vt Shifman \& Thelwall 2009; Shifman 2014: 169; Laineste \& Voolaid 2020: 52).

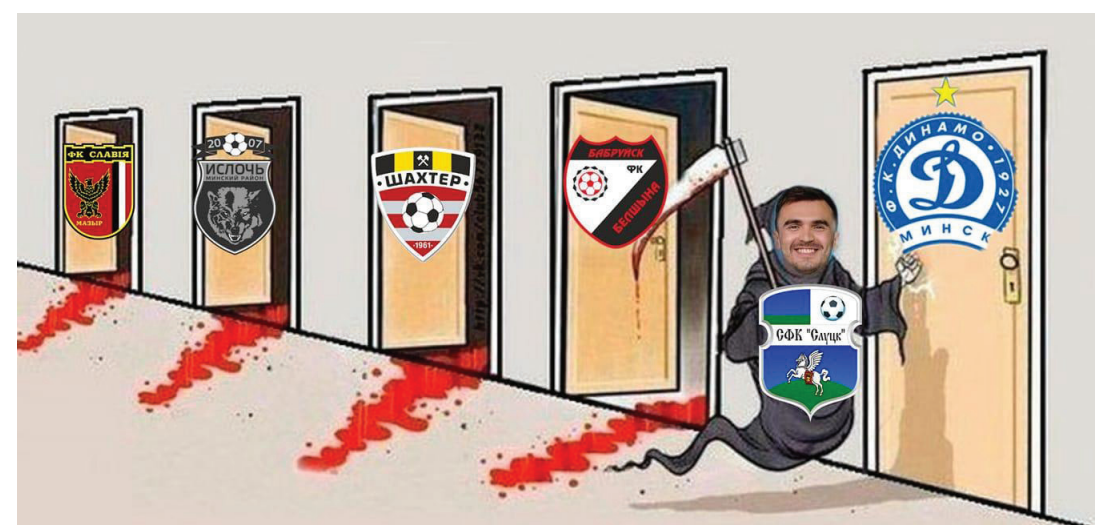

Joonis 21. Enne iga FK Slutski mängu tegid fännid sellise meemi, mis vihjas FK Slutski võidule. Meemimall oli sama, uksesildid vahetusid vastavalt järgmistele klubidele, kellega kohtuti (https: / / www.facebook.com / photo.php?fbid=592540104802679\&set =gm.265869557927725\&type=3\&theater $\&$ ifg=1 - vaadatud 21.02.2021).

\section{Kokkuvõtteks}

Päriselus jalgpallimängudel osalemise võimaluse puudumisel pidid jalgpallifännid kasutama võrgusuhtlust jalgpalliklubidega. Eesti ja Valgevene jalgpalli juhtumiuuringud avavad veebipõhised toimetulekustrateegiad, mida kriisisituatsiooni sattunud fännid ja klubid kasutavad. Analüüs näitab, et fännid hoidsid eriolukorra ajal ühendust meeskondadega, keda nad enne pandeemiat toetasid (nagu illustreerib Eesti näide), kuid enneolematu olukord ajendas leiutama ka täiesti uusi toetusvorme (näiteks FK Slutsk Worldwide Facebooki grupp).

Eesti jalgpalliklubid tegutsesid aktiivselt, kasutades juba varasemalt sissetöötatud rutiini ja traditsioone, aga ilmselgelt tekkis kriisiolukorras vajadus ka suhtlemine klubi jälgijate ja fännidega üle vaadata, et ärajäänud mängudega seotud infovahetuse asemel suunata rõhk nutikatele lahendustele ja tekitada virtuaalset kogukonnatunnet. 
Üks olulisi tähelepanekuid ja järeldusi Eesti kohta ilmnes selles, et mida paremini oli klubielu, sh sotsiaalmeediaturundus, korraldatud koroonaeelses tavaolukorras, seda paremini suudeti jätkata kriisiajal ning loominguliselt fänne ja klubi jälgijaid köita. Mõlemal juhul tekkis nii-öelda uus kvaliteet, et piirangute aeg üheskoos üle elada (nt \#saamehakkama ja \#üksklubiükspere Eesti klubide lehtedel ja \#weallloveslutsk FK Slutsk Worldwide lehel) ja ka sportlastele kaasa elada. Ühelt poolt jätkus uues olukorras sportlaste elu trenni tehti isoleeritult, iga üksiku sportlase enda vastutus oli väga suur ja oluline. Teisalt tuli klubidel nii olukorraga toimetuleku kui ka infoandmise eesmärkidel toetajatega pidevas suhtluses olla, pakkudes neile põnevat tegevust (väljakutsed jne).

Pandeemia ei muutnud mitte ainult klubide ja fännide kommunikatsioonimustrit (päriselust virtuaalmaailma), vaid mõjutas ka parasotsiaalse ja sotsiaalse suhtluse vahekorda. Hoolimata kahe riigi erinevast olukorrast oli neil ühine tendents, et jalgpallurid ja klubide esindajad suhtlesid fännidega aktiivsemalt kui tavaolukorras. FK Slutsk Worldwide juhtumi puhul seisid erakordsete asjaoludega silmitsi ainult fännid, samal ajal kui mängijad jätkasid tavapäraseid treeninguid ja matše. Kui Eesti klubide varasem edukas suhtlemine aitas lävida nende varasemate fännidega, siis kõik FK Slutski rahvusvahelised fännid olid väga hiljutised ja neil puudus varasem eluline kogemus selle klubi toetamisel. Uued fännamise vormid nõudsid seega uusi loomingulisi lahendusi ja suhtlusviise. FK Slutski juhtkond ja mängijad on nende uute oludega edukalt kohanenud ja taganud fännidega mõnusa dialoogi.

Nii Eesti klubid kui ka FK Slutski Worldwide Facebooki rühmad kasutasid oma sõnumites huumorit, kuid naljades pigem välditi COVID-19 teemat. Sport ja jalgpall on suuresti meelelahutus ja mõlema juhtumi näitel ilmnes, kuidas sotsiaalmeedias pakuti positiivset alternatiivi ahistavale koroonateemale, mis eriolukorra-aegses elus tuletas ennast nagunii pidevalt meelde. Või veelgi enam - võimaldati koroonaviirusega seonduvat kui peavoolumeedia põhiteemat ajutiselt üldse unustada. Mõlemal juhul süstiti kogukonnale positiivsust, ka meelelahutusliku tegevuse ja huumori kaudu; leiti võimalusi, et asendada ärajäänud võistlusi, nt klubi edukate mängude korduste näitamistega, mida oli võimalik koos vaadata ja vestlusruumis kommenteerida. Toimus ka FK Slutski mängude ühisvaatamisi Zoomis. Selline positiivne tegevuskava koos paindlikkuse ja loovusega on näidanud, et sport ja fännikultuur võivad ellu jääda ka tõsise murrangu ajal.

Käesolev ühisartikkel keskendus üksnes pandeemiaaja esimesele Euroopalainele, tulevikus on huvipakkuv uurida jalgpalliklubide tegevust pikemal ajaskaalal, laiendada klubide ringi ning võrrelda eri riikide jalgpalliklubide ja fännikogukondade toimetulekut ja testida sama meetodit teiste spordialade 
fännitegevuse peal. Meie uurimuses mängisid väga olulist rolli Eesti ja Valgevene kui kahte täiesti erinevasse poliitilisse kultuuriruumi kuuluva riigi jalgpallijuhtumid. Kuigi artiklis ei keskendunud me poliitikale, on selge, et rohujuuretasandi tegevus on mõjutatud poliitilistest otsustest, mis iseäranis kriisiolukorras võivad eri riikides kardinaalselt erineda.

\section{Tänusõnad}

Kirjutis on seotud Eesti Kirjandusmuuseumi uurimisprojektidega EKM 8-2/20/3 "Folkloori narratiivsed ja uskumuslikud aspektid" ja EKKD65 "Kuidas allikatest saab kultuur: eesti aines Eesti Kirjandusmuuseumi kogudes ja andmebaasides", selle valmimist toetas Euroopa Liit Euroopa Regionaalarengu Fondi kaudu (Eesti-uuringute Tippkeskus, TK 145). Autorite eriline tänu kuulub artikli anonüümsetele retsensentidele kõigi asjakohaste märkuste ja soovituste eest.

\section{Kommentaarid}

1 2018. aastal Eesti Kirjandusmuuseumi folkloristika osakonna korraldatud üle-eestilise koolipärimuse kogumisvõistluse küsitluskava sisaldas küsimust õpilaste meelisspordialade kohta. Nii tüdrukute kui ka poiste vastustes oli lemmikspordialana esikohal jalgpall (Eesti kooliõpilaste lemmikspordialade ülevaade anti ettekandes Voolaid 2020a).

2 Saaremaa kohaliku meedia andmetel oli suurim COVID-19 viirusekolle Eestis 2020. aasta kevadise laine ajal Saaremaa VK ja Milano Powervolley kohtumise tribüün 5. märtsil Kuressaares. Piisknakkusena levivale viirusele anti hoogu juurde fännipasunate abiga ja see langes aerosoolina tribüünil olevatele inimestele. Võrkpallimängult sai terviseameti hinnangul nakkuse 37 inimest. Neist vaid veerandi jagu puutus kokku itaallaste võrkpallimeeskonnaga ja 28 inimest nakatus tribüünil. Teada on, et meeskonnaga seotud inimestest põdes koroonaviiruse läbi pea kümmekond inimest. Tuvastatud haige oli ka sloveenlasest kohtunik (Vinni 2020).

\section{Arhiiviallikad}

Eesti Kirjandusmuuseumi folkloristika osakonna teadusarhiiv EFITA (kataloog EFITA F37-001). 


\section{Kirjandus}

Adetunji, Akinbiyi 2013. A Discursive Construction of Teasing in Football Fandom: The Context of the South-Western Nigerian Viewing Center. Discourse \& Society 24 (2), lk 147-162 (doi: 10.1177/0957926512469392).

Benigni, Vince \& Porter, Lance \& Wood, Chris 2009. The rant: How online fan culture is revolutionizing college football. Journal of Electronic Communication 19 (3), lk 1-13 (http://www.cios.org/EJCPUBLIC/019/2/019345.html - 21. veebruar 2021).

Boschilia, Bruno \& Moraes, Letícia Cristina Lima \& Wanderley, Marchi Junior 2021. Football and COVID-19: the effects of the pandemic on training and performance of South American and Brazilian referees. Soccer \& Society 22 (1-2), lk 58-65 (doi: 10.1080/14660970.2020.1829597).

Carroll, R. 1980. Football hooliganism in England. International Review of Sport Sociology 15 (2), lk 77-92 (doi: 10.1177/101269028001500205).

Cleland, Jamie \& Dixon, Kevin 2015. 'Black and whiters': the relative powerlessness of 'active' supporter organization mobility at English Premier League football clubs. Soccer \& Society 16 (4), lk 540-554 (doi: 10.1080/14660970.2014.891988).

Derbaix, Christian \& Decrop, Alain 2011. Colours and scarves: an ethnographic account of football fans and their paraphernalia. Leisure Studies 30 (3), lk 271-291 (doi: 10.1080/02614367.2010.527356).

Fiadotava, Anastasiya 2021. Internetifolkloor globaalse pandeemia ajal: COVID-19 Valgevene veebihuumoris. Mäetagused 79, lk 87-112 (doi: 10.7592/MT2021.79.fiadotava).

Giles, David C. 2002. Parasocial interaction: A review of the literature and a model for future research. Media psychology 4 (3), lk 279-305 (doi: 10.1207/s1532785xmep0403_04).

Giles, David C. 2010. Parasocial relationships. Eder, Jens \& Jannidis, Fotis \& Schneider, Ralf (toim). Characters in fictional worlds: Understanding imaginary beings in literature, film, and other media. Berlin \& New York: Walter de Gruyter, lk 442-456.

Guerrero-Calderón, Berni 2021. The effect of short-term and long-term coronavirus quarantine on physical performance and injury incidence in high-level soccer. Soccer \& Society 22 (1-2), lk 85-95 (doi: 10.1080/14660970.2020.1772240).

Hiiemäe, Reet \& Kalda, Mare \& Kõiva, Mare \& Voolaid, Piret 2020. Koroonakriisi rahvapärased väljendused Eestis: Folkloori taaskasutus kui toimetulekuviis. Keel ja Kirjandus 12, lk 1011-1032 (https://keeljakirjandus.ee/ee/uncategorized/koroonakriisirahvaparased-valjendused-eestis/ - 1. märts 2021).

Horky, Thomas 2021. No sports, no spectators - no media, no money? The importance of spectators and broadcasting for professional sports during COVID-19. Soccer \& Society 22 (1-2), lk 96-102 (doi: 10.1080/14660970.2020.1790358).

Horton, Donald \& Wohl, R. Richard 1956. Mass communication and para-social interaction: Observations on intimacy at a distance. Psychiatry 19 (3), lk 215-229 (doi: 10.1080/00332747.1956.11023049). 
Howard, Robert Glenn 2008. The vernacular web of participatory media. Critical Studies in Media Communication 25 (5), lk 490-513 (doi: 10.1080/15295030802468065).

Hughson, John 1998. Among the thugs: The new ethnographies of football supporting subcultures. International Review for the Sociology of Sport 33 (1), lk 43-57 (doi: 10.1177/101269098033001004).

Jenkins, Henry 2006. Fans, bloggers, and gamers: Exploring participatory culture. New York \& London: New York University Press.

Jenkins, Henry \& Ford, Sam \& Green, Joshua 2018. Spreadable media: Creating value and meaning in a networked culture. New York: New York University Press.

Karu, Lenel 2020. Spordifännidelt nõuab uus elu maski ja keelab pasunad. Tartu Postimees 16. september (https://tartu.postimees.ee/7063186/spordifannidelt-nouabuus-elu-maski-ja-keelab-pasunad - 1. märts 2021).

Kennedy, David \& Kennedy, Peter 2021. English premier league football clubs during the covid-19 pandemic: business as usual? Soccer \& Society 22 (1-2), lk 27-34 (doi: 10.1080/14660970.2020.1797498).

Kossakowski, Radosław \& Besta, Tomasz 2018. Football, conservative values, and a feeling of oneness with the group: a study of Polish football fandom. East European Politics and Societies 32 (4), lk 866-891 (doi: 10.1177/0888325418756991).

Krikščiūnas, Povilas 2020. Chapter 8: Between Culture and Subculture: The Case of Lithuania's Basketball Fans. Būgienè, Lina (toim). The Storytelling Human: Lithuanian Folk Tradition Today. Boston: Academic Studies Press, lk 209-243.

Kuperjanov, Maris 2020. Koroonaviiruse SARS-CoV-2 algusfaasi vastukaja (sotsiaal) meedias. Mäetagused 76, lk 5-28 (doi: 10.7592/MT2020.76.kuperjanov).

Kytölä, Samu 2012. Peer Normativity and Sanctioning of Linguistic Resources-inUse - on Non-Standard Englishes in Finnish Football Forums Online. Blommaert, Jan \& Leppänen, Sirpa \& Pahta, Päivi \& Räisänen, Tiina (toim). Dangerous Multilingualism: Northern Perspectives on Order, Purity and Normality. London: Palgrave Macmillan, lk 228-260 (doi: 10.1057/9781137283566_11).

Laineste, Liisi 2016. From Joke Tales to Demotivators. A Diachronic Look at Humorous Discourse in Folklore. Traditiones 45 (3), lk 7-25 (doi: 10.3986/traditio2016450302).

Laineste, Liisi \& Voolaid, Piret 2020. Tabust saab kommunikatsioon: dopinguteemaline huumor kultuuride dialoogis. Mäetagused 77, lk 31-60 (doi: 10.7592/MT2020.77. laineste_voolaid).

McCormack, Ange 2020. Missing sport? These Adelaide soccer fans have quietly sparked a cult following of a league in Belarus. $A B C$ News 14. mai (https://www.abc.net.au/ triplej/programs/hack/adelaide-soccer-fans-rally-around-obscure-team-in-belarus/122 48408?fbclid=IwAR33VfjvpZEc-MwpGWPFrbGRUGY0NcQPb2txftwmnFDB3zUS50 Ez-bhGEJo - 1. märts 2021).

McGraw, A. Peter \& Warren, Caleb 2010. Benign violations: Making immoral behavior funny. Psychological science 21 (8), lk 1141-1149 (doi: 10.1037/e722992011-021). 
OTV 2020 = Aleksandr Lukashenko: Khokkei - luchshee antivirusnoe lekarstvo! Obshchenatsional'noye televideniye 28. märts (https://ont.by/news/aleksandr-lukashenkohokkej-luchshee-antivirusnoe-lekarstvo - 1. märts 2021).

Parnell, Daniel \& Bond, Alexander John \& Widdop, Paul \& Cockayne, David 2021. Football Worlds: business and networks during COVID-19. Soccer \& Society 22 (1-2), lk 19-26 (doi: 10.1080/14660970.2020.1782719).

Piata, Anna 2016. When metaphor becomes a joke: Metaphor journeys from political ads to internet memes. Journal of Pragmatics 106, lk 39-56 (doi: 10.1016/j.pragma.2016.10.003).

Richardson, Brendan \& Turley, Darach 2006. Support Your Local Team: Resistance, Subculture, and the Desire For Distinction. Pechmann, Connie \& Price, Linda (toim). NA - Advances in Consumer Research 33. Duluth, MN: Association for Consumer Research, lk 175-180.

Rivers, Damian J. \& Ross, Andrew S. 2019. "This channel has more subs from rival fans than Arsenal fans": Arsenal Fan TV, football fandom and banter in the new media era. Sport in Society, lk 1-20 (doi: 10.1080/17430437.2019.1706492).

Roosad Pantrid 2020 = Roosad Pantrid - NÕMME KALJU FÄNNID. Facebooki grupp 23. aprill (https://www.facebook.com/pantrid/posts/2958807020845167 - 1. märts 2021).

Ruddock, Andy \& Hutchins, Brett \& Rowe, David 2010. Contradictions in media sport culture: The reinscription of football supporter traditions through online media. European Journal of Cultural Studies 13 (3), lk 323-339 (doi: 10.1177/1367549410363200).

Shifman, Limor \& Thelwall, Mike 2009. Assessing global diffusion with Web memetics: The spread and evolution of a popular joke. Journal of the American society for information science and technology 60 (12), lk 2567-2576 (doi: 10.1002/asi.21185).

Shifman, Limor 2014. Memes in digital culture. Cambridge, MA: MIT press.

Soccernet $2020=$ Tõsiuskliku jalgpallifänni hingeelu. "Tunnistan - mõnda üksikut Valgevene liiga mängu vaatasin ...”. Silm peale. Youtube 4. juuni (https://www.youtube.com/watch?v=FK7OMPUAZ-s\&fbclid=IwAR1RQ8d8CiGLtFGGMcXFLctKI1A0P4ysnPUi6wpL-BVIho-agwf05Xjm6s - 1. märts 2021).

Sorokin, Siim. 2018. Character Engagement and Digital Community Practice: A Multidisciplinary Study of "Breaking Bad". Dissertationes Folkloristicae Universitatis Tartuensis 27. Tartu: Tartu Ülikooli Kirjastus (https://dspace.ut.ee/handle/10062/59057 1. märts 2021).

Spinda, John SW \& Earnheardt, Adam C. \& Hugenberg, Lawrence W. 2009. Checkered flags and mediated friendships: Parasocial interaction among NASCAR fans. Journal of Sports Media 4 (2), lk 31-55 (doi: 10.1353/jsm.0.0041)

Tovar, Jorge 2021. Soccer, World War II and coronavirus: a comparative analysis of how the sport shut down. Soccer \& Society 22 (1-2), lk 66-74 (doi: 10.1080/14660970.2020.1755270).

Vinni, Raul 2020. Terviseamet: viirus puhuti laiali fännipasunatest. Saarte Hääl 23. aprill (https://saartehaal.postimees.ee/6956358/terviseamet-viirus-puhuti-laialifannipasunatest?_ga - 1. märts 2021). 
Voolaid, Piret 2014. Olümpiavõitja kui rahvuskangelane: folkloristlik vaade ühele dopingujuhtumile. Mäetagused 58, lk 53-84 (doi: 10.7592/MT2014.58.voolaid).

Voolaid, Piret 2020a. Sportlase eeskuju ja lemmikspordialade tähtsus eesti noortele. Eesti Kirjandusmuuseumi folkloristika osakonna konverents "Toimetulekustrateegiad 2: päevikupidamisest meemiloomeni”. Ajakava ja teesid. 21.-22. september 2020. Äksi Motorantšo, Tartumaa: Tartu: EKM Teaduskirjastus, lk 11-12.

Voolaid, Rasmus 2020b. Suur intervjuu: Kõik Eesti tipud läbi käinud Kaspar Paur oma perekonnast, kergejõustikurekorditest, lisatrennist, koondisest, Kaljust. Soccernet 21. märts (https://soccernet.ee/artikkel/suur-intervjuu-koikeesti-tipud-labi-kainud-kaspar-paur-oma-perekonnast-kergejoustikurekorditestlisatrennist-koondisest-kaljust?fbclid=IwAR0jAELblZy 3 PoQh 1 gtc eAAOZuJOo8hvo1Ry6jy4OLwPSEIwkTFhg3dYk8 - 1. märts 2021).

Webb, Tom 2021. The future of officiating: analysing the impact of COVID-19 on referees in world football. Soccer \& Society 22 (1-2), lk 12-18 (doi: 10.1080/14660970.2020.1768634).

Weitz, Eric 2017. Humour and social media. The European Journal of Humour Research 4 (4), lk 1-4 (doi: 10.7592/ejhr2016.4.4.weitz).

Woodward, Jack 2021. Football's dramatic pause - when Saturday doesn't come. Soccer \& Society 22 (1-2), lk 8-11 (doi: 10.1080/14660970.2020.1763065).

Yuksel, Mujde \& Labrecque, Lauren I. 2016. "Digital buddies": parasocial interactions in social media. Journal of Research in Interactive Marketing 10 (4), lk 305-320 (doi: 10.1108/jrim-03-2016-0023).

\title{
Summary
}

\section{Constructing fandom at the time of corona crisis: The case studies of Estonian and Belarusian football clubs}

\author{
Anastasiya Fiadotava \\ Junior Researcher \\ Department of Folkloristics, Estonian Literary Museum \\ Centre of Excellence in Estonian Studies \\ anastasiya.fiadotava@folklore.ee \\ Piret Voolaid \\ Senior Research Fellow \\ Department of Folkloristics, Estonian Literary Museum \\ Executive Manager of the Centre of Excellence in Estonian Studies \\ piret.voolaid@folklore.ee
}

Keywords: Belarusian and Estonian folklore, COVID-19 pandemic, fan culture, humour, football, Internet memes, social media, sport folklore 
The comparative study analyses the relationship between sports culture and the COVID-19 crisis based on the case studies of fan groups in Estonia and Belarus. Sports and the COVID-19 pandemic are closely interconnected. In the Estonian case, the official analysis results testify that during the first COVID-19 wave in spring 2020 the most affected region in the country was Saaremaa Island, where the virus was literally blown into the air by fan bugles at the international volleyball competition held on 4-5 March 2020. Belarusian sports events did not have such dramatic repercussions, but there were also coronavirus hotbeds in several popular football clubs. The two countries had different approaches to sports events. In Estonia, as in most European countries, all sports competitions and games were banned from 12 March to 17 May 2020, during the state of emergency, but in Belarus, normal sports life continued (except in the cases when there was a COVID-19 hotbed in a sports club). While Estonian football fans were forced to stay home and wait for the games to continue, Belarusian fans, unlike the rest of the world, enjoyed championship games and stadium life. The unique situation in Belarus drew the attention of world football fans to Belarusian football. During the pandemic, most fan activities took place online, making social media the most appropriate environment for this joint study.

In this article, we compare the activities of Estonian and Belarusian football clubs during the first wave of the COVID-19 pandemic and analyse how fan activities continued on Facebook. We also describe the general situation in the field of sports during the pandemic.

Our analysis shows that the pandemic not only changed the communication pattern between clubs and fans (from real life to the virtual world), but also affected the ratio of parasocial and social interaction. Despite the different situations in the two countries, there was a tendency for football players and club representatives to interact with fans more actively than usual. New forms of fandom required new creative solutions and ways of communicating, which involved humour, (audio)visual media and an emphasis on positive agenda.

Anastasiya Fiadotava ( $\mathrm{PhD}$ ) on Eesti Kirjandusmuuseumi folkloristika osakonna nooremteadur ja Eesti-uuringute Tippkeskuse liige. Tema huvialad on folkloristika, huumoriuuringud ja perekonna rahvaluule. Tal on Valgevene ajaloo magistrikraad Valgevene Riiklikust Ülikoolist ja folkloristika doktorikraad Tartu Ülikoolist. Tema doktoritöö keskendus Valgevene perekonna humoorikale rahvaluulele.

Anastasiya Fiadotava (PhD) is Junior Research Fellow at the Department of Folkloristics of the Estonian Literary Museum, and at the Centre of Excellence in Estonian Studies. Her fields of interest include folkloristics, humour studies, and family lore. She holds an MA in Belarusian history from Belarusian State University, and a PhD from the University of Tartu. Her PhD thesis focuses on humorous family lore in Belarus.

anastasiya.fiadotava@folklore.ee 
Piret Voolaid (PhD) on Eesti Kirjandusmuuseumi folkloristika osakonna vanemteadur, Eesti-uuringute Tippkeskuse tegevjuht. Peamised uurimisteemad on folkloori lühivormid (mõistatuste liigiline mitmekesisus ja sotsiokultuurilised kontekstid, vanasõnade kaasaegsed kasutuskontekstid), laste- ja noortefolkloor kui ühiskondlike muutuste ja hoiakute indikaator, meediafolkloor, sh interneti sotsiaalmeedia ilmingud, multimodaalsed ja visuaalsed folkloorivormid (nt paröömiline grafiti, piltmõistatused) kui nüüdisühiskonna sünkreetilised kultuurinähtused. Viimastel aastatel on tegelenud spordifolkloristika ehk spordifolkloorile keskenduva uurimissuuna arendamisega, analüüsides dopingufolkloori, spordi rolli identiteedinarratiivide konstrueerimisel. Koostanud mitmeid folkloori lühivormide andmebaase, avaldanud teadusartikleid, toimetanud artiklikogumikke ja ajakirjade erinumbreid.

Piret Voolaid (PhD) is Senior Research Fellow at the Department of Folkloristics of the Estonian Literary Museum, and the Executive Manager of the Centre of Excellence in Estonian Studies. She defended her PhD ("Estonian Riddles as a Folklore Genre in a Changing Cultural Context") in the field of Estonian and comparative folklore at the University of Tartu in 2011. Her current interests include minor forms of folklore (subgenres of Estonian riddles, proverbs in their various contemporary contexts), children's and youth folklore, Internet, and sports lore. She has compiled academic comprehensive databases of the subgenres of riddles (droodles, joking questions, compound puns, abbreviation riddles, etc.), and a database of graffiti. She has written several studies on the topic and compiled popular editions on the basis of the database materials. She has guest-edited special issues of the journals Folklore: EJF and Mäetagused, and has been editor of some monographs.

piret.voolaid@folklore.ee 